\title{
Copy Number Variation in the Horse Genome
}

\author{
Sharmila Ghosh ${ }^{1}$, Zhipeng Qu ${ }^{2}$, Pranab J. Das ${ }^{1}$, Erica Fang ${ }^{1}$, Rytis Juras ${ }^{1}$, E. Gus Cothran ${ }^{1}$, Sue McDonell ${ }^{3}$, \\ Daniel G. Kenney ${ }^{4}$, Teri L. Lear ${ }^{5}$, David L. Adelson ${ }^{2}$, Bhanu P. Chowdhary ${ }^{6}$, Terje Raudsepp ${ }^{1 *}$ \\ 1 Department of Veterinary Integrative Biosciences, College of Veterinary Medicine, Texas A\&M University, College Station, Texas, United States of America, 2 School of \\ Molecular and Biomedical Science, The University of Adelaide, Adelaide, South Australia, Australia, $\mathbf{3}$ New Bolton Center, School of Veterinary Medicine, University of \\ Pennsylvania, Pennsylvania, United States of America, 4 Ontario Veterinary College, University of Guelph, Guelph, Ontario, Canada, 5 M.H. Gluck Equine Research Center, \\ Veterinary Science Department, University of Kentucky, Lexington, Kentucky, United States of America, 6 New Research Complex, Qatar University, Al Tarfa, Doha, Qatar
}

\begin{abstract}
We constructed a 400K WG tiling oligoarray for the horse and applied it for the discovery of copy number variations (CNVs) in 38 normal horses of 16 diverse breeds, and the Przewalski horse. Probes on the array represented 18,763 autosomal and $\mathrm{X}$-linked genes, and intergenic, sub-telomeric and chrY sequences. We identified 258 CNV regions (CNVRs) across all autosomes, chrX and chrUn, but not in chrY. CNVs comprised $1.3 \%$ of the horse genome with chr12 being most enriched. American Miniature horses had the highest and American Quarter Horses the lowest number of CNVs in relation to Thoroughbred reference. The Przewalski horse was similar to native ponies and draft breeds. The majority of CNVRs involved genes, while $20 \%$ were located in intergenic regions. Similar to previous studies in horses and other mammals, molecular functions of CNV-associated genes were predominantly in sensory perception, immunity and reproduction. The findings were integrated with previous studies to generate a composite genome-wide dataset of 1476 CNVRs. Of these, 301 CNVRs were shared between studies, while 1174 were novel and require further validation. Integrated data revealed that to date, 41 out of over 400 breeds of the domestic horse have been analyzed for CNVs, of which 11 new breeds were added in this study. Finally, the composite CNV dataset was applied in a pilot study for the discovery of CNVs in 6 horses with XY disorders of sexual development. A homozygous deletion involving AKR1C gene cluster in chr29 in two affected horses was considered possibly causative because of the known role of AKR1C genes in testicular androgen synthesis and sexual development. While the findings improve and integrate the knowledge of CNVs in horses, they also show that for effective discovery of variants of biomedical importance, more breeds and individuals need to be analyzed using comparable methodological approaches.
\end{abstract}

Citation: Ghosh S, Qu Z, Das PJ, Fang E, Juras R, et al. (2014) Copy Number Variation in the Horse Genome. PLoS Genet 10(10): e1004712. doi:10.1371/journal. pgen.1004712

Editor: Gregory S. Barsh, Stanford University School of Medicine, United States of America

Received April 10, 2014; Accepted August 26, 2014; Published October 23, 2014

Copyright: (C) 2014 Ghosh et al. This is an open-access article distributed under the terms of the Creative Commons Attribution License, which permits unrestricted use, distribution, and reproduction in any medium, provided the original author and source are credited.

Data Availability: The authors confirm that all data underlying the findings are fully available without restriction. The array is available at Agilent Technologies; Design ID \#030025, Cat. No G4124A. The aCGH data are available at NCBI GEO accession GSE55266

Funding: TR and BPC were supported by Texas Agrilife Research, LINK Endowment and American Quarter Horse Association, DA and ZQ were supported by The University of Adelaide; ZQ was supported by a China Scholarship Council scholarship. The funders had no role in study design, data collection and analysis, decision to publish, or preparation of the manuscript.

Competing Interests: The authors have declared that no competing interests exist.

* Email: TRaudsepp@crm.tamu.edu

\section{Introduction}

The significance of gene duplication in long-term evolutionary changes was already recognized over 40 years ago by Susumu Ohno [1]. Yet, systematic genome-wide discovery and functional interpretation of inter- and intraspecific copy number variations (GNVs) in genes and non-genic DNA sequences, started in the past decade with foundational studies in humans [2,3] and mice [4], followed by genome-wide (GW) CNV discovery in chicken [5], cattle [6], dogs [7,8] and other domestic species (see $[9,10])$. It is now well established that CNVs are a common feature of vertebrate genomes. Typically, they are DNA sequence variants from at least 50 base-pairs (bp) to over several megabase-pairs $(\mathrm{Mb})$ in size that are involved in deletions, insertions, duplications and translocations, causing structural differences between genomes [11,12]. In terms of the total number of DNA base-pairs, CNVs are responsible for more heritable sequence differences $(0.5-1 \%)$ between individuals than SNPs $(0.1 \%)[11,12,13]$.
One of the central goals of CNV research has been determining their association with genome instability, genetic diseases and congenital disorders. It is thought that CNVs, as a major source of inter-individual genetic variation, could explain variable penetrance of Mendelian and polygenic diseases, and variation in the phenotypic expression of complex traits [14,15]. Indeed, CNVs have been associated with common complex and polygenic disorders in humans affecting a broad range of biological processes, such as immune response, autoimmunity and inflammation [3,16,17]; musculoskeletal [18,19] and cardiovascular systems [20,21]; neurodevelopment, cognition and behavior $[22,23]$, and sexual development and reproduction $[24,25,26,27,28]$.

The availability of whole genome (WG) sequence draft assemblies combined with the advances in array-based technologies and next generation sequencing (NGS), have prompted CNV research in all main domestic animal species (reviewed by $[9,10]$ ) with the most advanced information currently available for cattle $[6,29,30]$, pigs [31], and dogs [32,33,34]. 


\section{Author Summary}

Genomes of individuals in a species vary in many ways, one of which is DNA copy number variation (CNV). This includes deletions, duplications, and complex rearrangements typically larger than 50 base-pairs. CNVs are part of normal genetic variation contributing to phenotypic diversity but can also be pathogenic and associated with diseases and disorders. In order to distinguish between the two, detailed knowledge about CNVs in the species of interest is needed. Here we studied the genomes of 38 normal horses of 16 diverse breeds, and identified 258 CNV regions. We integrated our findings with previously published horse CNVs and generated a composite dataset of $\sim 1400$ CNVRs. Despite this large number, our analysis shows that CNV research in horses needs further improvement because the current data are based on $10 \%$ of horse breeds and that most CNVRs are studyspecific and require validation. Finally, we analyzed CNVs in horses with disorders of sexual development and found in two male pseudo-hermaphrodites a large deletion disrupting a group of genes involved in sex hormone metabolism and sexual differentiation. The findings underline the possible role of CNVs in complex disorders such as development and reproduction.

In horses, five studies report about the discovery of CNVs in the whole genome [35,36,37,38] or in gene exons [39]. Attempts have also been made to associate CNVs with equine diseases [36], adaptations [38] and phenotypic traits $[37,39]$. While these studies set a foundation for understanding the role of $\mathrm{CNVs}$ in equine biology, the current information is inadequate for efficient discovery of variants affecting equine health and disorders. This is because the studies have used different GNV discovery platforms, the number of breeds and individuals in some studies is very limited, and the majority of reported CNVs are studyspecific and not validated by two or more independent studies. Also, the available information has not been integrated into a composite dataset to facilitate the analysis of known CNVs and the discovery of new ones.

The aim of this study is to improve the current rather limited knowledge of CNVs in horses by their genome-wide discovery in multiple individuals of additional diverse horse breeds. Using a custom-made WG tiling array we generate a CNV map for the horse genome and integrate this with the previous CNV studies into a composite dataset. Finally, we carry out a pilot CNV analysis in horses with disorders of sexual development to test the utility of the array and the integrated dataset for the discovery of variants involved in equine complex disorders.

\section{Results}

\section{The Texas-Adelaide horse whole-genome tiling array}

Texas A\&M University (USA) and The University of Adelaide (Australia) collaborated to create a whole-genome (WG) $400 \mathrm{~K}$ tiling array which was produced and printed by Agilent Technologies (Design ID \#030025), and designated as the Texas-Adelaide array. The probes on the array represented 18,763 autosomal and X-linked genes, and intergenic, subtelomeric and chrY sequences. Median genomic distance between the probes on the array was $7.5 \mathrm{~kb}$; this distance was lower $(4 \mathrm{~kb})$ in sub-telomeric regions, and higher $(\sim 20 \mathrm{~kb})$ in the $\mathrm{Y}$ chromosome. Before using the array for CNV discovery in horses, the platform was tested for performance quality. Self-to-self control hybridizations (Figure Sla) showed $1.55 \%$ of False Discovery Rate (FDR) - an indication that the array design, fabrication, and array genomic hybridization $(\mathrm{aCGH})$ procedures were optimal. As a proof-of principle, female-to-male hybridizations between two half-sib Thoroughbreds, Twilight (female) and Bravo (male), showed massive loss in the $\mathrm{X}$ chromosome and a gain in the $\mathrm{Y}$ chromosome in the male, whereas only one CNV was detected in an autosome, chr3 (Figure Slb). Hybridization quality was assessed by measuring Derivative Log Ratio Standard Deviation (DLRSD) which calculates probe-to probe $\log$ ratio noise and is typically $<0.3$ for good quality hybridizations. The DLRSD values for all hybridizations with blood DNA from Twilight and Bravo were $<0.2$. Therefore, and because the oligonucleotides on the array were derived from the sequences of these two horses, DNA of Twilight and Bravo was used as a reference for all aCGH experiments: Twilight for females and Bravo for males. Further, because our DNA collection from horse breeds contained samples isolated from blood and hair, an additional self-to-self hybridization was conducted using DNA from blood and hair of one male Quarter Horse QH3-H528 (Table S1). Blood DNA gave good quality results with DLRSD $=0.14$, whereas consistent and high level hybridization noise was observed for hair DNA (DLRSD $=0.41$ ) (Figure S1c). Due to this, GNVs in all samples were called with stringent criteria: $\log _{2}$ ratio alterations higher than 0.5 over 5 neighboring probes - a necessary compromise between calling CNVs with confidence and missing a few true calls. With median probe spacing of $7.5 \mathrm{~kb}$ on the array, this allowed detection $\mathrm{CNVS}$ of about $30 \mathrm{~kb}$, and in probe-dense regions even smaller. We concluded that the performance of the equine $400 \mathrm{~K}$ TexasAdelaide whole-genome $\mathrm{CGH}$ array was optimal for the discovery of CNVs in the horse genome.

\section{CNV discovery and construction of a whole-genome CNV map for the horse}

The aCGH data are available at NCBI GEO accession GSE55266. Collectively, $950 \mathrm{CNV}$ calls were made across 36 horses, with an average of 26.4 calls per individual (Table 1; Table S3). The number of CNV calls was the highest in two American Miniature Horses (59 and 46) and the lowest in American Quarter Horses (12 and 14), whereas the number of calls per individual was not significantly different between blood and hair DNA $(P=0.07$; Table 1$)$ at the settings of $\log _{2} \pm 0.5$ over 5 probes. The number and distribution of CNVRs in the two Przewalski horses were similar to those in domestic horses (Table 1, Table S4). Because the Thoroughbred served as a reference, by default all the 950 CNV calls recorded in other breeds were also present in the Thoroughbred, though inversely with respect to gains and losses. However, because the Thoroughbred was compared with multiple individuals, the same CNV had different $\log _{2}$ values, and that is why the Thoroughbreds were not included in the comparisons of GNV metrics.

The ADM-2 algorithm arranged adjacent and overlapping CNV calls (CNVs) within and between individual horses into 258 GNV regions (CNVRs; Table S5) of which 114 were shared between at least 2 individuals of the same or different breeds, while 144 were private and found only in one individual. Two GNVRs were found in two or more individuals of the same breed but not in other breeds and were tentatively considered as breed-specific: a $14 \mathrm{~kb}$ loss in chr9 in Exmoor ponies, and a $39 \mathrm{~kb}$ loss in chr20 in Swiss Warmblood horses (Table S4).

Based on the 258 CNVRs, a whole genome CNV map for the horse was constructed (Figure 1) details of which are summarized in Table 2. The mean size of CNVRs was $110 \mathrm{~kb}$ ranging from $1 \mathrm{~kb}$ to $2.5 \mathrm{Mb}$. The CNVRs occupied $1.15 \%$ of the equine 
Table 1. Breed- and individual-wise summary of CNV calls in horses.

\begin{tabular}{|c|c|c|c|c|}
\hline Horse breed & Source of DNA for aCGH & CNV calls per individual & Gains & Losses \\
\hline Akhal-teke 1 & Blood & 37 & 12 & 25 \\
\hline Akhal-teke 2 & Blood & 26 & 13 & 13 \\
\hline American Miniature Horse 1 & Blood & 59 & 16 & 43 \\
\hline American Miniature Horse 2 & Hair & 46 & 4 & 42 \\
\hline American Quarter Horse 1 & Blood & 12 & 0 & 12 \\
\hline American Quarter Horse 2 & Blood & 21 & 2 & 19 \\
\hline American Quarter Horse 3 & Blood & 14 & 10 & 4 \\
\hline Arabian 1 & Blood & 21 & 17 & 4 \\
\hline Arabian 2 & Hair & 17 & 0 & 17 \\
\hline Belgian 1 & Blood & 31 & 14 & 17 \\
\hline Belgian 2 & Hair & 14 & 1 & 13 \\
\hline Caspian Pony 1 & Blood & 40 & 16 & 24 \\
\hline Caspian Pony 2 & Hair & 12 & 1 & 11 \\
\hline Clydesdale 1 & Blood & 25 & 6 & 19 \\
\hline Clydesdale 2 & Hair & 16 & 1 & 15 \\
\hline Exmoor Pony 1 & Blood & 29 & 15 & 14 \\
\hline Exmoor Pony 2 & Hair & 18 & 8 & 10 \\
\hline Fell Pony 1 & Blood & 25 & 11 & 14 \\
\hline Fell Pony 2 & Hair & 47 & 11 & 36 \\
\hline Friesian 1 & Blood & 29 & 6 & 23 \\
\hline Friesian 2 & Blood & 39 & 10 & 29 \\
\hline Friesian 3 & Blood & 41 & 9 & 32 \\
\hline Friesian 4 & Blood & 22 & 12 & 10 \\
\hline Mongolian Native Horse1 & Hair & 22 & 1 & 21 \\
\hline Mongolian Native Horse2 & Hair & 18 & 2 & 16 \\
\hline Percheron 1 & Blood & 17 & 11 & 6 \\
\hline Percheron 2 & Hair & 12 & 1 & 11 \\
\hline Przewalski's Horse 1 & Fibroblasts & 21 & 5 & 16 \\
\hline Przewalski's Horse 2 & Fibroblasts & 21 & 3 & 18 \\
\hline Sorraia 1 & Blood & 36 & 8 & 28 \\
\hline Sorraia 2 & Hair & 18 & 1 & 17 \\
\hline Standardbred 1 & Blood & 17 & 7 & 10 \\
\hline Standardbred 2 & Blood & 44 & 13 & 31 \\
\hline Swiss Warmblood 1 & Blood & 23 & 1 & 22 \\
\hline Swiss Warmblood 2 & Blood & 30 & 6 & 24 \\
\hline Swiss Warmblood 3 & Blood & 29 & 9 & 20 \\
\hline Thoroughbred 1 & Blood & Male reference & $n / a$ & $\mathrm{n} / \mathrm{a}$ \\
\hline Thoroughbred 2 & Blood & Female reference & $\mathrm{n} / \mathrm{a}$ & $\mathrm{n} / \mathrm{a}$ \\
\hline Average & & 26.4 & 7.3 & 19.1 \\
\hline Median & & 22.5 & 7.5 & 17.0 \\
\hline
\end{tabular}

The number of calls per individual was not significantly different (Student's T-test $p=0.07$ ) between hair and blood DNA.

doi:10.1371/journal.pgen.1004712.t001

genome and were distributed over all horse chromosomes, except the $\mathrm{Y}$, with the highest enrichment in chromosomes $12(9.7 \%)$ and $20(3.0 \%)$. Even though chr12 is the gene richest chromosome in the horse genome ( 15 genes $/ \mathrm{Mb}$ ), there was no overall correlation between GNV enrichment and gene density. For example, the enrichment values for the second and third gene densest chromosomes, chrl1 and chr13, were $0.02 \%$ and $0.28 \%$, respectively (Table 2). Likewise, we did not observe CNV enrichment in sub-telomeres, as previously reported for humans [40]: the array contained 5,716 sub-telomeric probes, though only 10 CNVRs were detected in these regions in horses.

In general, losses $(173 ; 67 \%)$ prevailed over gains $(63 ; 24 \%)$, although 6 horses had more gains than losses (Table 1). Twentytwo CNVRs (8.5\%) were complex involving both losses and gains in different individuals (Table 2, Table S3). Even though aCGH on diploid samples cannot discriminate between copies of alleles 


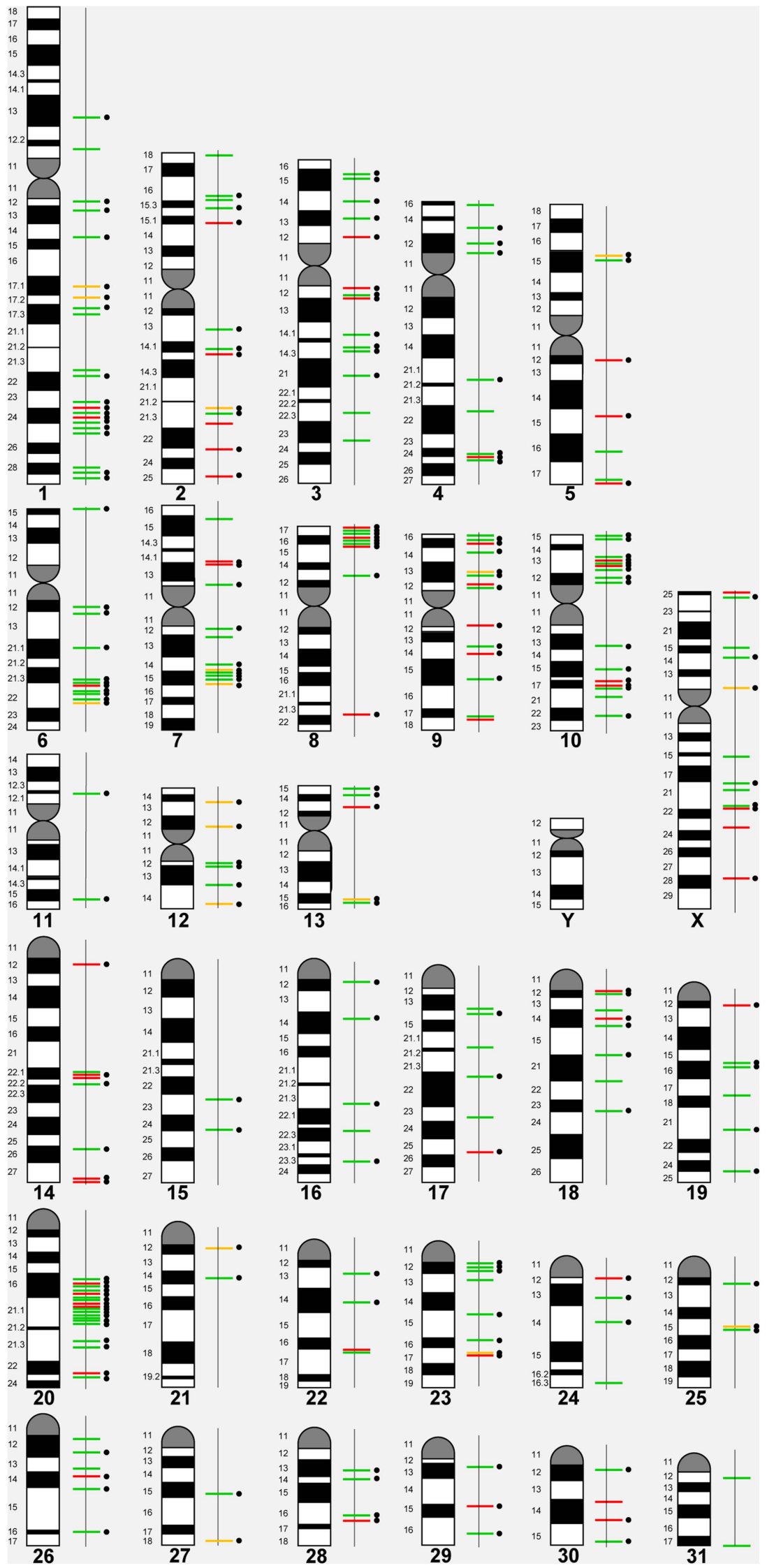

Figure 1. A CNVR map of the horse genome. Green line - loss; red line - gain; yellow line - complex; black dots - genes involved. doi:10.1371/journal.pgen.1004712.g001 


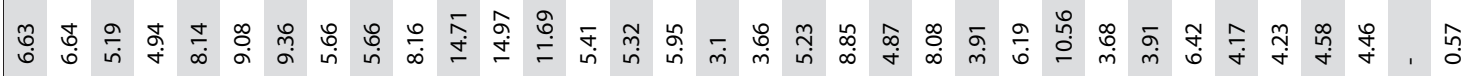

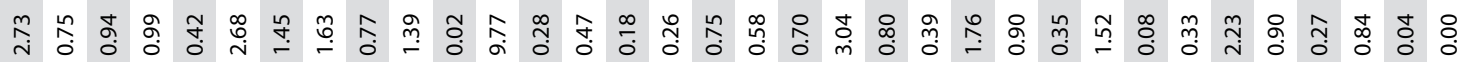

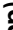
oิ

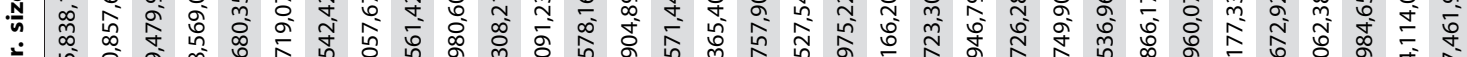

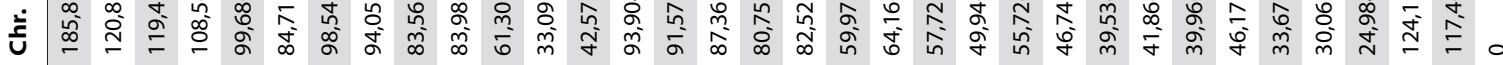

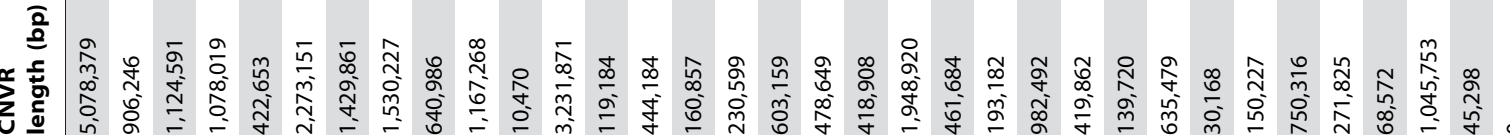

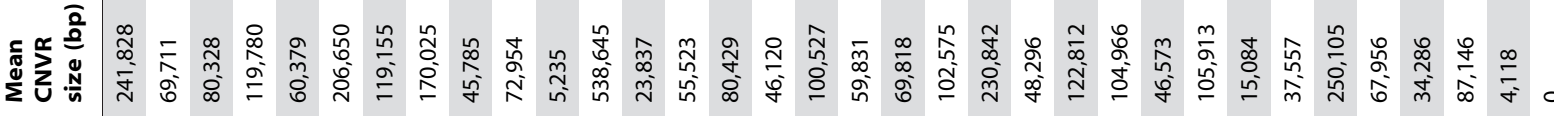
它 


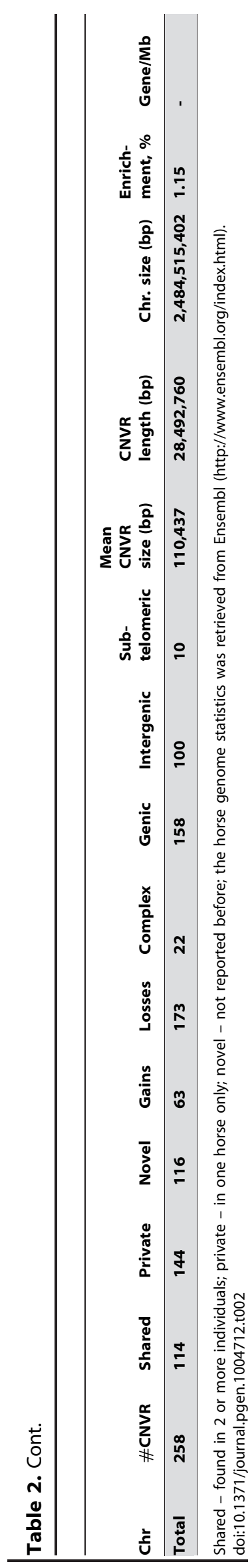

and thus, distinguish between heterozygous and homozygous CNVs, two gains and 14 losses were tentatively considered homozygous because of $\log _{2}$ alterations over 2.0 (Table S6). Homozygosity of 8 losses was confirmed by qualitative PCR (Fig. S2).

\section{Gene content of CNVRs and functional categories of copy} number variable genes

The majority $(82 \%)$ of horse CNVRs contained one or more known Ensembl (http://www.ensembl.org/index.html) horse genes (158 CNVRs) or non-horse mammalian reference genes (54 GNVRs) (Table S7), while 46 GNVRs (18\%) were located in intergenic regions (Table S8). Gene containing CNVRs were also predominant in individual chromosomes with the exception of chr31 which was enriched with intergenic variants Fig. 2. However, we consider calls for intergenic CNVRs tentative and subject to change as the annotation of the horse genome is still in progress.

Altogether, the CNVRs involved 805 protein-coding genes (750 Ensembl genes, 33 non-Ensembl genes and 22 horse mRNAs; Table S7) but also non-coding small and long RNA genes, and pseudogenes. The largest CNVRs with the highest number of genes corresponded to clusters of olfactory and non-olfactory Gprotein coupled receptors (GPGRs) or to immunity related genes, such as immunoglobulins, T-cell receptors, and $\mathrm{MHC}$ protein complex genes - a typical feature of CNVRs in all mammalian genomes studied so far $[3,30,32,39,41,42]$. Likewise, Gene Ontology (GO) analysis indicated that equine copy number variable genes are predominantly involved in biological processes and molecular functions related to transmembrane signal transduction, chemo-attractant sensory perception, immune response and steroid metabolism (Fig. 3; Table S9). Notably, 5 copy number variable genes from this study were associated with known OMIA (http://omia.angis.org.au/home/) phenotypes for immune, reproductive or neuromuscular diseases (Table 3), though none of the OMIA records involved horses or CNVs. The GNVR overlapping with the $B M P R 1 B$ gene has been earlier reported in horses and is of interest because of a possible role in the regulation of the rate of ovulation [39].

\section{Composite CNV dataset for the horse genome}

Comprehensive knowledge of CNVs in normal horse populations, within and across breeds, is a prerequisite for the discovery of variants that contribute to equine genetic diseases and disorders. Therefore, we aligned the 258 CNVRs identified in this study with previously published CNV data for the horse [35,36,37,38,39]. Altogether, we found records of about $2041 \mathrm{CNVs}$ and CNVRs (calling criteria vary between studies). These were further consolidated, based on adjacent locations or partial overlaps, into 1476 GNVRs of which 301 CNVRs (20\%) were shared between two or more studies (Table S10, Fig. 4). The majority of shared CNVRs involved genes associated with olfactory reception (50 CNVRs) and membrane transport (49 GNVRs) but also genes involved in transcription (30 CNVRs), cell cycle regulation (12 CNVRs) and RNA genes (34 CNVRs). Expectedly, CNVRs that were found in more than 100 horses and reported by all 6 studies exclusively involved olfactory receptors. Comparative analysis also revealed that novel (study-specific) CNVRs predominated over shared ones in all 6 studies (Fig. 4). Novel CNVRs of functional interest from this study involved genes related to sperm-egg interaction and fertilization in chr4:19.8-19.9 Mb; a developmental gene SOX2 in chr19:20.1 Mb; an X-linked region harboring genes of circadian pacemaker function chrX:83.8-84.0 Mb, and a complex CNVR in chrUn:225-226 kb with cancer related genes. 
Notably, the latter two GNVRs were found in more than 10 horses each. Details of all novel and shared CNVRs are presented in Table S10.

\section{Experimental validation of CNVRs by quantitative PCR and FISH}

Nineteen GNVRs were validated by quantitative PCR (qPCR) using array probe-specific primers (Table S2). The regions were selected upon three criteria - size, gene content and novelty. The smallest tested GNVR was $4 \mathrm{~kb}$ and the largest $2 \mathrm{Mb} ; 13$ involved clusters of horse genes, and 6 were novel. A summary of qPCR results are presented in Figure S3 and Table S11. All selected CNVRs were first tested in the discovery horses and then analyzed in more individuals of the same breed to identify possible breedspecific tendencies. Overall, qPCR observations agreed well $(P$ value $<0.05$ ) with the array $\mathrm{CGH}$ data for all discovery horses and for other animals of the same breed. For example, it confirmed a complex CNVR in chr27 involving CSMD1 gene (CUB and Sushi multiple domains 1) which encodes a transmembrane and a candidate tumor suppressor protein [43]. Copy numbers in this region were tested on 11 breeds with at least 2 individuals each and showed a gain in native ponies, draft breeds and the Przewalski horse, and a loss in American Miniature horses in relation to the Thoroughbred (Fig. 5A-B). Likewise, qPCR confirmed a CNVR in chr20 (Fig. 5C) which has been found only in this study and in indigenous plateau horses [38]. However, we found some differences too between the two data sets: e.g., while qPCR confirmed a loss in chr20:32.0-32.4 Mb and chr17:18.8-19.0 Mb in the discovery Swiss Warmblood and Mongolian horses (Table S3), respectively, inclusion of additional horses from the same breeds resulted in a significant gain in these regions (Fig. S3). Also, initial qPCR confirmed a loss in chr7:74.8$74.9 \mathrm{Mb}$ in the two discovery Swiss Warmblood horses (Table S3) but no significant losses were found when more individuals were added. These minor discrepancies can be attributed to intra-breed variation: array CGH was based on 2 to 4 individuals, while qPCR involved 4 or more horses per breed (Figure S3, Table S11).

Two CNVRs, a complex $200 \mathrm{~kb}$ gain-loss region in chr1:114.0$114.2 \mathrm{Mb}$ and a $2.2 \mathrm{~kb}$ gain in chrUn: $529-531 \mathrm{~kb}$ ) were validated by FISH using CNV-containing CHORI-241 BAC clones 132B13 (Fig. S4) and 91B23 (Fig. 6), respectively. Clear differences in copy numbers between individual horses, as well as between homologous chromosomes of the same horse were observed. Additionally, the GNVR in chrUn was mapped to horse chr19q12-q13 (Fig. 6).

\section{Discovery of CNVs in horses with XY disorders of sexual development (DSDs)}

Finally, we carried out a pilot study to test the utility of the tiling array and the integrated CNV data set (Table S10) for the discovery of CNVs involved in equine XY disorders of sexual development (XY DSD). Selection of the phenotype was based upon studies in humans suggesting contribution of CNVs to XY DSDs $[25,27,28]$. Array CGH experiments were carried out in 6 affected horses (Table 4): all had normal male 64,XY karyotype with an intact $S R Y$ gene, abnormal male or female gonads, and female or female-like external phenotype [44]. We determined 179 GNVs (average 30 calls per individual) and 107 CNVRs, of which 83 were common and shared with normal equine populations, and 24 GNVRs were novel (Table 5). Only 3 novel CNVRs were shared between two or three XY DSD horses, while the remaining 21 were private and present in just one animal. Protein coding or miRNA genes with functions in cell cycle regulation, transcription and posttranscriptional processing were involved in 14 novel GNVRs. None of the GNV-genes had known functions in sexual differentiation or development.

Analysis of common CNVRs for highly aberrant $\log _{2}$ values detected two likely homozygous deletions (Table 5): a $26 \mathrm{~kb}$ loss in chr7 $\left(\log _{2}-2.2\right)$ and a $\sim 200 \mathrm{~kb}$ loss in chr29 $\left(\log _{2}-3.5\right)$. The latter was of particular interest because it was found in two closely related American Standardbreds with very similar male-pseudohermaphrodite phenotypes (H348 and H369; Table 4). The GNVR was also present in 10 out of the 38 normal horses (Table S3) including one American Standardbred, though with a moderate aberration value $\left(\log _{2 a v e r a g e}-0.7\right)$ compared to $\log _{2}=-3.5$ in the two XY DSD horses. Most notably, the CNVR involved at least 4 members of the aldo-keto reductase $A K R 1 C$ gene family, known to be critical in the backdoor pathway of dihydrotestosterone (DHT) synthesis and sexual development $[45,46]$. A schematic overview of the CNVR, including the involved genes and aberration profiles of all 47 array probes in the region, is presented in Fig. 7. Homozygosity of the deletion was confirmed by fluorescence in situ hybridization (FISH) with a BAC clone (CHORI-241-23N13) spanning the deletion. The BAC hybridized to chr29 in control animals but not in the two XY DSD horses, whereas a control BAC (CHORI-241-76H613) with the

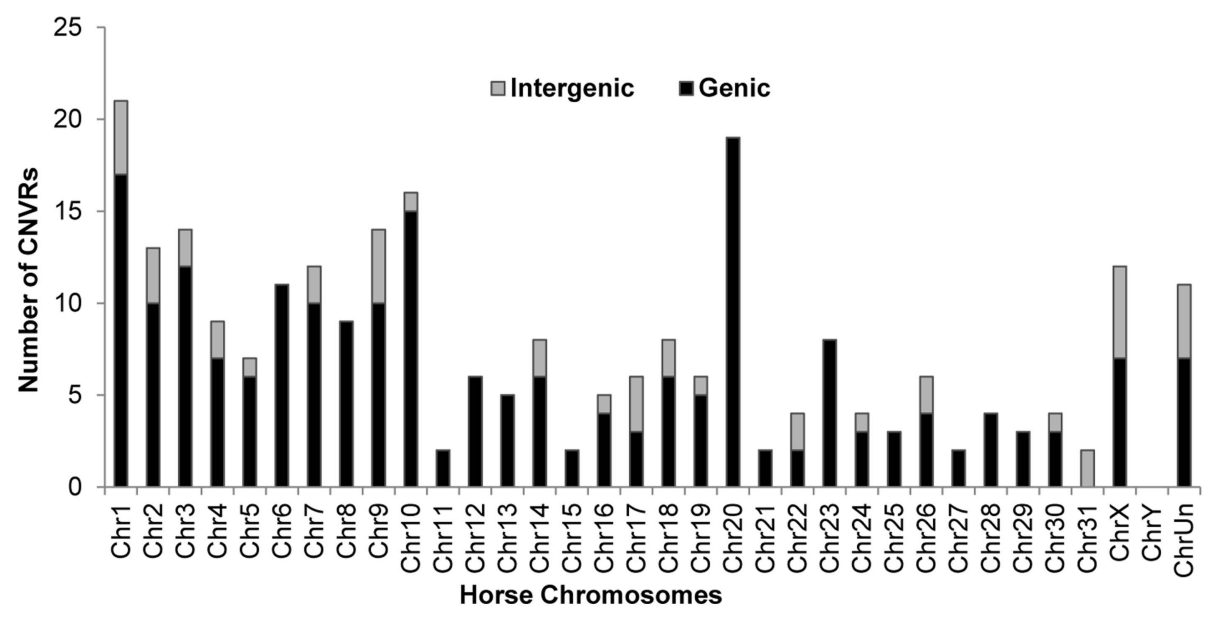

Figure 2. Chromosome-wise distribution of genic and intergenic CNVRs in the horse genome. doi:10.1371/journal.pgen.1004712.g002 
Molecular Function

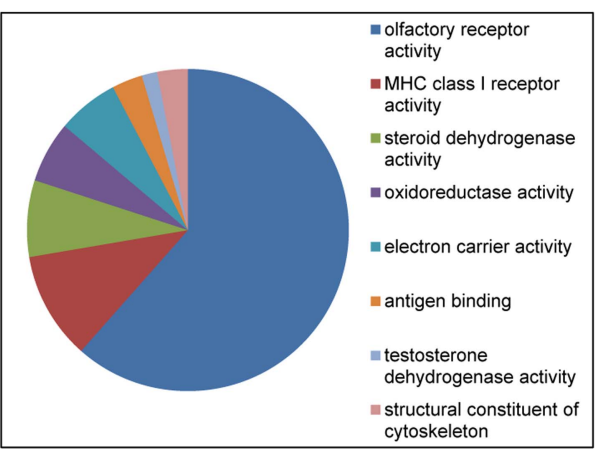

Biological Process

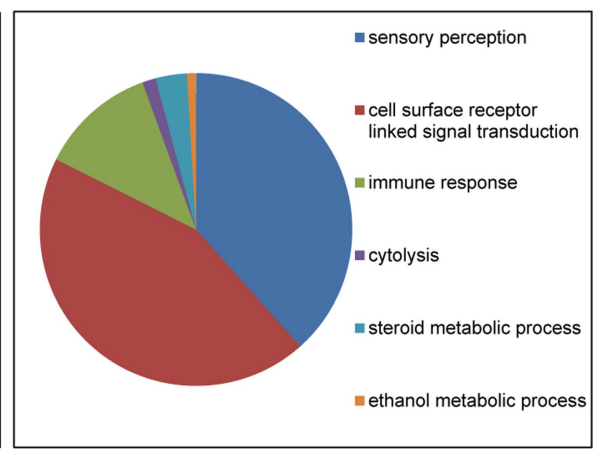

Figure 3. Gene Ontology classifications of copy number variable genes in horses. doi:10.1371/journal.pgen.1004712.g003

CREM gene from a non-CNVR in chr29 [47] hybridized equally in the XY DSD horses and controls (Fig. 7). Homozygosity of the deletion was further confirmed by PCR showing that primers designed inside the CNVR amplified genomic DNA of control horses and the remaining $4 \mathrm{XY}$ DSD horses, but not of the two male-pseudohermaphrodite American Standardbreds (H348 and H369; Fig. 7). Though primers designed outside the CNVR, amplified the DNA by PCR in all horses - an evidence that the DNA quality of the two Standardbreds was acceptable. We theorized that the homozygous deletion involving $A K R 1 C$ genes in the two male-pseudohermaphrodite horses might be the risk factor for abnormal sexual development.

\section{Discussion}

During just the past two years, five studies have addressed the phenomenon of copy number variation in the horse genome $[35,36,37,38,39]$ contributing to our knowledge about the genomic landscape of $\mathrm{CNV}_{\mathrm{s}}$ and their role in inter-individual variation in horses. Despite the progress, lessons from humans $[48,49,50]$ and more recently from dogs $[7,34]$, show that efficient biomedical application of this information requires integration of data from many more populations and individuals and the use of comparable methodological platforms[48,49,50].

Here we report about the construction of a $400 \mathrm{~K}$ high-density WG tiling oligoarray for the horse and its application for the discovery of CNVs in 38 normal horses of 16 diverse breeds, as well as in 6 horses with congenital disorders. Probes on the array were designed to detect $\mathrm{CNV}$ s in 18,763 equine autosomal and Xlinked genes but also in intergenic, sub-telomeric and $\mathrm{Y}$ chromosome sequences. Regarding genome coverage, our CNV discovery platform most closely resembled the recently reported WG 1.3 M NimbleGen CGH array [38], but essentially complemented the exon CGH array by Doan and colleagues [39] and the studies based on WG SNP50 BeadChip [37,51]. The latter is of a magnitude lower density and not specifically designed for CNV capture. Also, as shown in humans and cattle, the efficiency of CNV discovery is lower in SNP platforms compared to CNV focused arrays [29,50]. While the future direction for CNV research in any species is probably next generation sequencing (NGS), the approach has as yet found only limited application in horses: for the discovery of CNVs in the genome of a Quarter Horse mare [35] and for the discovery of segmental duplications in 6 horse breeds and the donkey [52].

A unique feature of our CGH array was the inclusion of probes from the $\mathrm{Y}$ chromosome and sub-telomeric regions. This was because CNVs and segmental duplications are known to be an integral part of the architecture of the mammalian Y chromosome [53,54], while sub-telomeres are hotspots of DNA breakage and repair, and undergo structural rearrangements more frequently than the rest of the genome $[40,55]$. Despite the almost 6,000 subtelomeric probes with lower than average spacing $(\sim 4 \mathrm{~kb} v \mathrm{~s}$. $\sim 7 \mathrm{~kb}$ across the genome) on the array, only 10 GNVs were detected in sub-telomeres and none in the $\mathrm{Y}$ chromosome (Table 2). It is likely that the complex sub-telomeric sequences are either missing or underrepresented in the current horse sequence assembly [56], due to which it is possible that the probes designed from the ends of the chromosomes, did not originate from actual sub-telomeres.

Poor representation of centromeric/pericentromeric and telomeric/sub-telomeric sequences is a common shortcoming of all draft genome assemblies. Whilst the horse may be different to humans or other species in terms of subtelomeric sequences, this can only be rigorously shown by sequencing BAC clones from these regions, preferably with long-read single molecule technology such as a Pacific Biosciences instrument to resolve long repeats. Such an approach was recently successfully applied to resolve regions of segmental duplications in the finished genome sequence of humans [57].

The Y chromosome, on the other hand, has acquired and amplified novel sequences, as well as sequences from the rest of the genome [58]. Thus, it is likely that many potential copy number variable Y probes did not pass the 'uniqueness' test by BLAST and were dropped from the array (see Material and Methods for details).

\section{Integration and comparison of the CNV data for the horse}

The present and all previous CNV studies in horses $[35,36,37,38,39]$ differ by discovery platforms, genome coverage, resolution, the study cohorts and analytical methods (Table 6). Therefore, the overall numbers, size ranges and chromosomal distribution of CNVs vary between the studies. For example, it has been shown that due to analytical reasons, CGH-based studies tend to detect more losses than gains [59]. This holds true for the Agilent WG array in the present study and also the Nimblegen WG array [38], though [38] slightly more gains were detected with the Agilent exon array [39] (Table 6). The latter was attributed to the large number of losses in the reference animal compared to the Thoroughbred (Twilight) genome sequence assembly EquCab2 [56]. In contrast, gains vastly predominate (97\%) among the CNVs found by NGS in a Quarter Horse mare [35]. Apparent 
CNVs in Equine Health and Congenital Disorders

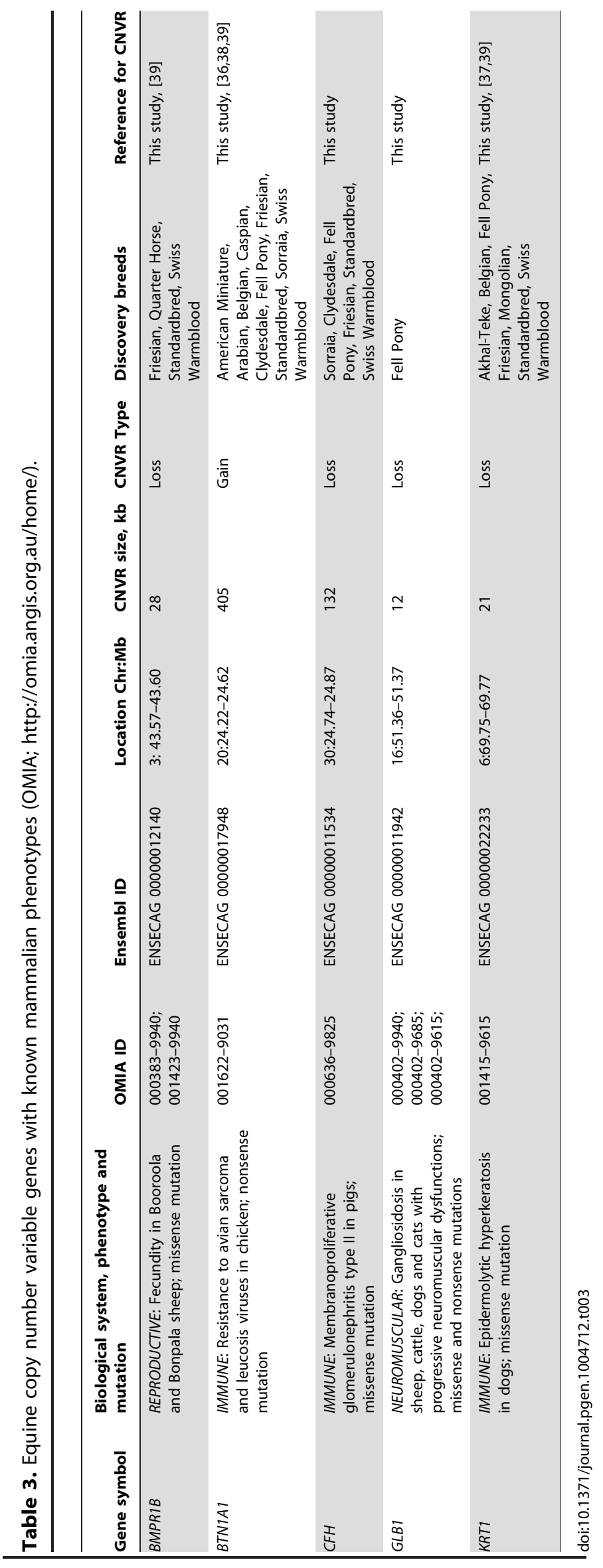




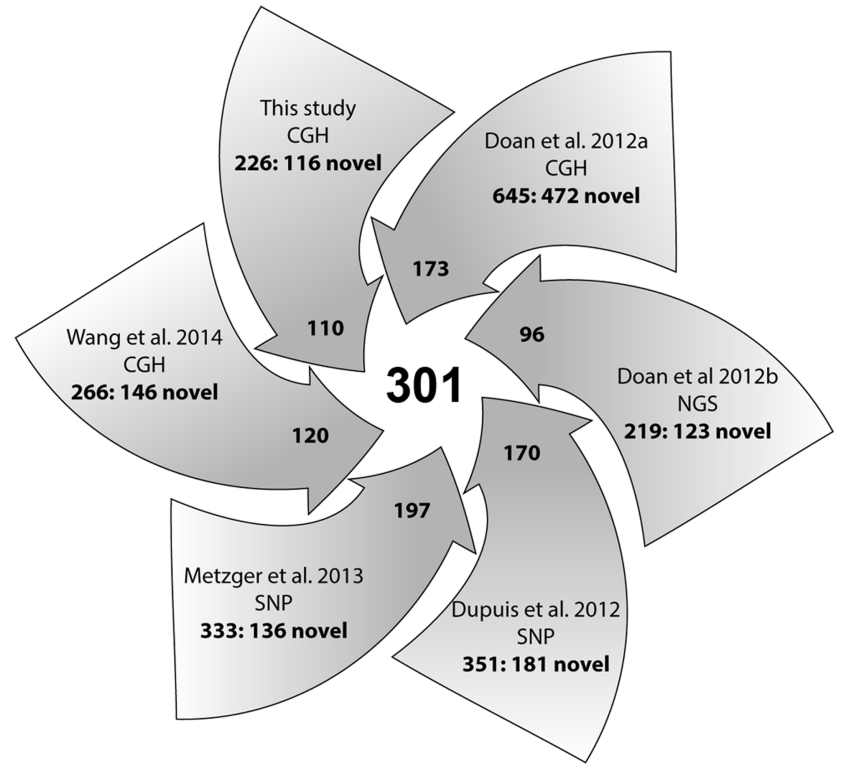

Figure 4. A summary diagram of all CNV studies in horses and their contribution to the integrated CNV dataset. Numbers in arrow-heads denote the contribution of each study to the common pool of $\mathbf{3 0 1}$ shared CNVRs; numbers in arrow-tails denote the total and novel (separated by colon) CNVRs per study; CGH, SNP and NGS denote the platforms used for CNV detection.

doi:10.1371/journal.pgen.1004712.g004

differences in GNV calling algorithms and thresholds (Table 6), on the other hand, are responsible for the variation in the number of $\mathrm{CNVs}$, their size and the criteria for merging individual GNVs into GNVRs. For example, in this study we
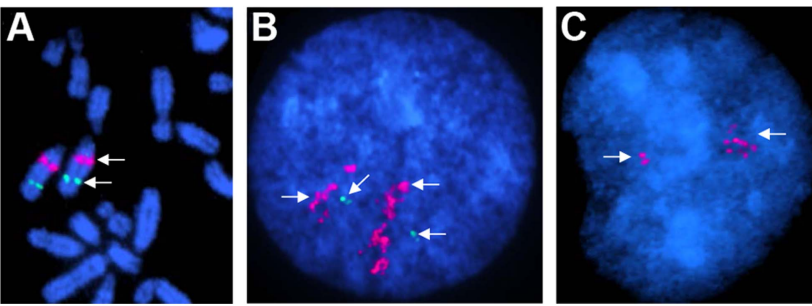

Figure 6. Chromosomal assignment and validation of a CNVR in chrUn (529-531 kb) by FISH. A. Mapping the CNVR to chr19q12q13 by FISH with BAC 132B13 (red); green - a control BAC with UMPS gene in chr19q21 [93]; B. The CNVR (red) in interphase chromosomes of a Percheron; green - a single-copy control probe; C. The CNVR (red) in interphase chromosomes of a Thoroughbred (Twilight). Note the difference in copy numbers between the Percheron and the Thoroughbred, as well as between homologous chromosomes. doi:10.1371/journal.pgen.1004712.g006

mainly reported GNVRs because this is how the ADM-2 algorithm analyses and assembles the CNV calls (CNVs) within and across individuals. Further, specific features of the probe/ array design, and not necessarily the number of probes, are responsible for the differences in the genomic distribution of discovered CNVs. So far, X-linked CNVs have been found only in this study and by Doan \& colleagues [39], and GNVs in chrUn only in this study. Surprisingly, the study with a three times denser 1.3 M Nimblegen array failed to detect GNVs in chrX, as well as in [38] chrs30 and 31 [38]. At the same time, the latter two small autosomes show the highest number of CNVs in the Quarter Horse mare [35]. Major differences are also in the size, diversity and origin of the study cohorts, ranging from just a few breeds and individuals $[35,38]$ to over 15 breeds (this study and [37]) and hundreds of individuals [36,37] (Table 6).

A

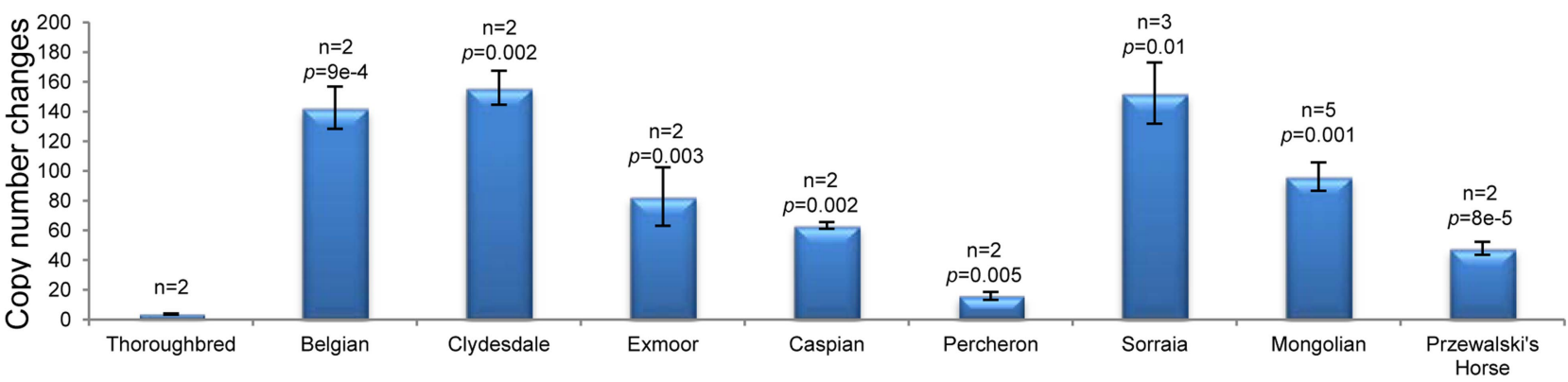

B

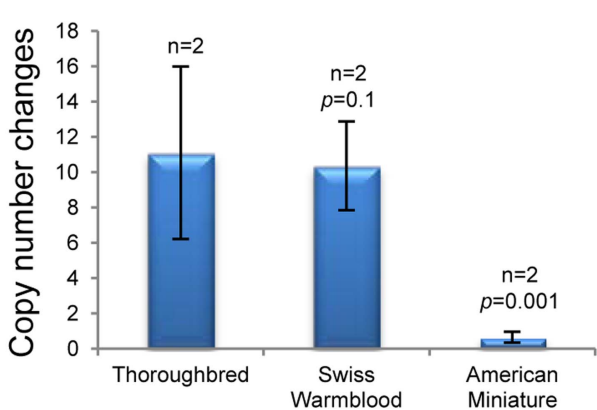

C

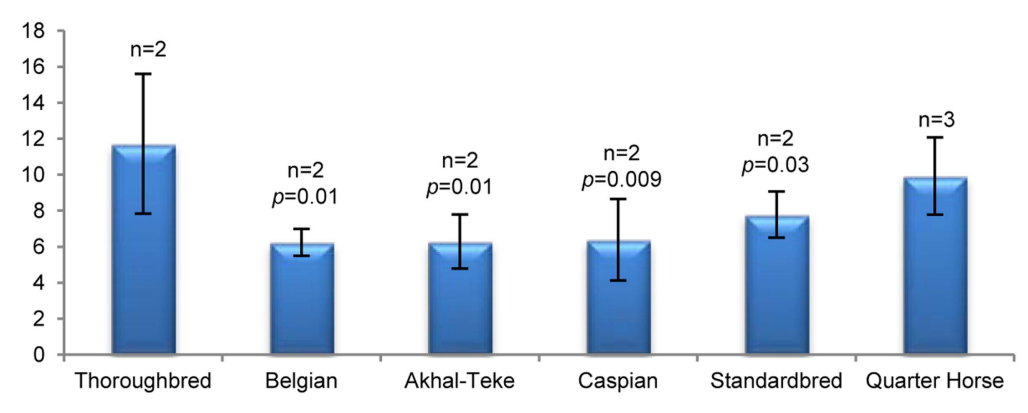

Figure 5. Validation of CNVRs by PCR. A. gains and B. losses in Chr27 (37.3 Mb; probe Gs_27_37371896) involving CUB and Sushi multiple domains 1 (CSMD1) gene; C. Loss in Chr20 (24.8 Mb; probe Eic_20_24841849) involving olfactory receptors; $n$ - number of individuals analyzed. doi:10.1371/journal.pgen.1004712.g005 
Table 4. Horses with SRY-positive XY DSDs analyzed in this study.

\begin{tabular}{|c|c|c|c|c|c|}
\hline Horse ID & Breed & Phenotype & Karyotype & $S R Y$ PCR & Reference \\
\hline H169 & Appaloosa & $\begin{array}{l}\text { Normal external genitalia; hypoplastic uterus; underdeveloped } \\
\text { mammary glands; estrous behavior }\end{array}$ & $64, X Y$ & pos & [44] \\
\hline H252 & Mixed warmblood & $\begin{array}{l}\text { Small ventrally located vulva between rear legs; abnormally } \\
\text { small uterus }\end{array}$ & $64, X Y$ & pos & [44] \\
\hline H348 & Standardbred, Arizona Helen & $\begin{array}{l}\text { Female-like external phenotype; rudimentary abdominal } \\
\text { gonads (testes) - male pseudohermaphrodite }\end{array}$ & $64, X Y$ & pos & [44] \\
\hline H369 & Standardbred Martha Maxine & $\begin{array}{l}\text { Female-like external phenotype; rudimentary abdominal } \\
\text { gonads (testes) - male pseudohermaphrodite }\end{array}$ & $64, X Y$ & pos & [44] \\
\hline H544 & Tennessee Walking Horse & $\begin{array}{l}\text { Female-like external phenotype; rudimentary abdominal } \\
\text { gonads (testes) - male pseudohermaphrodite }\end{array}$ & $64, X Y$ & pos & This study \\
\hline H546 & Thoroughbred & $\begin{array}{l}\text { Female-like external phenotype; rudimentary abdominal } \\
\text { gonads (testes) - male pseudohermaphrodite }\end{array}$ & $64, X Y$ & pos & This study \\
\hline
\end{tabular}

doi:10.1371/journal.pgen.1004712.t004

The many variables between the six studies (Table 6) obviously confound assessments based solely on GNV metrics, and it would probably be more appropriate to compare the actual CNVs/CNVRs reported. Therefore, and in order to obtain a comprehensive overview about the status of CNV discovery in horses, we integrated the GNVs or CNVRs from all six studies ([35,36,37,38,39], this study) according to their genomic locations into a composite dataset of 1476 CNVRs (Table S10). Of these, 301 are reported by at least two studies, while the remaining 1174 CNVRs are study-specific (novel; Fig. 4) and require further validation.

The integrated dataset is a needed resource for evaluating new CNV discoveries and gives an idea about the most intrinsic

Table 5. Novel and highly aberrant common (in bold font) CNVRs in XY DSD horses.

\begin{tabular}{|c|c|c|c|c|c|c|}
\hline Horse ID & Chr & Start & Stop & Size, kb & Gene symbol or sequence ID & $\log _{2}$ average \\
\hline H169 & 3 & $57,377,730$ & $57,394,356$ & 16.6 & Intergenic & -0.7 \\
\hline H546 & 4 & $95,018,254$ & $95,034,834$ & 16.5 & ENSECAG00000014506 & -1.0 \\
\hline H369 & 8 & $13,128,936$ & $13,134,708$ & 5.7 & MZT2B, TUBA3D & -1.0 \\
\hline H544 & 10 & $51,078,681$ & $51,119,659$ & 40.9 & Intergenic & -0.9 \\
\hline H545 & 12 & 619,419 & 638,513 & 19.0 & CSTF3 & -0.7 \\
\hline H544, H546 & 14 & $15,353,340$ & $15,560,610$ & 207.2 & ENSECAG00000002162 & -0.7 \\
\hline H544 & 14 & $29,406,214$ & $29,432,771$ & 26.5 & $T E T 2$ & -1.3 \\
\hline H369 & 15 & $14,237,934$ & $14,272,519$ & 34.5 & $B C L 2 L 11$ & -0.7 \\
\hline $\mathrm{H} 544$ & 15 & $44,348,596$ & $44,377,735$ & 29.1 & eca-mir-217, eca-mir-216a, eca-mir-216b & -1.1 \\
\hline H369 & 16 & $21,651,711$ & $21,683,467$ & 31.7 & Intergenic & -0.9 \\
\hline H546 & 16 & $65,654,753$ & $65,661,154$ & 6.4 & Intergenic & -1.1 \\
\hline H544 & 18 & $14,064,543$ & $14,101,261$ & 36.7 & JU909423 & -1.0 \\
\hline H546 & 18 & $60,925,026$ & $60,954,644$ & 29.6 & ENSECAG00000003850 & -1.2 \\
\hline $\mathrm{H} 252$ & 20 & $18,917,213$ & $18,969,026$ & 51.8 & $E 2 F 3$ & +0.8 \\
\hline H546 & 20 & $36,503,850$ & $36,508,477$ & 4.6 & SRSF3 & -1.0 \\
\hline H546 & 23 & $27,814,249$ & $27,838,233$ & 23.9 & $G L D C$ & +0.8 \\
\hline H544 & 23 & $46,897,740$ & $46,957,535$ & 59.7 & AK140548 & -0.9 \\
\hline H369 & 24 & $44,255,536$ & $44,269,279$ & 13.7 & Intergenic & -0.7 \\
\hline $\mathrm{H} 544$ & 25 & $22,614,255$ & $22,768,706$ & 154.4 & JO239254 & -0.5 \\
\hline H544 & 26 & $5,796,076$ & $5,840,516$ & 44.4 & TIGD1 & -1.2 \\
\hline $\mathrm{H} 252$ & 27 & $20,201,870$ & $20,232,375$ & 30.5 & MICU3 & -0.5 \\
\hline H369, H544, H546 & 28 & $18,833,995$ & $18,846,757$ & 12.7 & UBE2N & -1.1 \\
\hline $\mathrm{H} 252$ & $X$ & 203 & 366,729 & 366.5 & AKAP17A, ASMT, ZBED1, XG & -0.5 \\
\hline H544, H546 & $X$ & $98,506,468$ & $98,543,836$ & 37.3 & STAG2 & -1.1 \\
\hline H252 & 7 & $74,885,505$ & $74,911,413$ & 25.9 & OR56B4 & -2.2 \\
\hline H348, H369 & 29 & $28,640,862$ & $28,835,337$ & 194.4 & $A K R 1 C L 1, A K R 1 C 2, A K R 1 C 3, A K R 1 C 4$ & -3.5 \\
\hline
\end{tabular}

doi:10.1371/journal.pgen.1004712.t005 


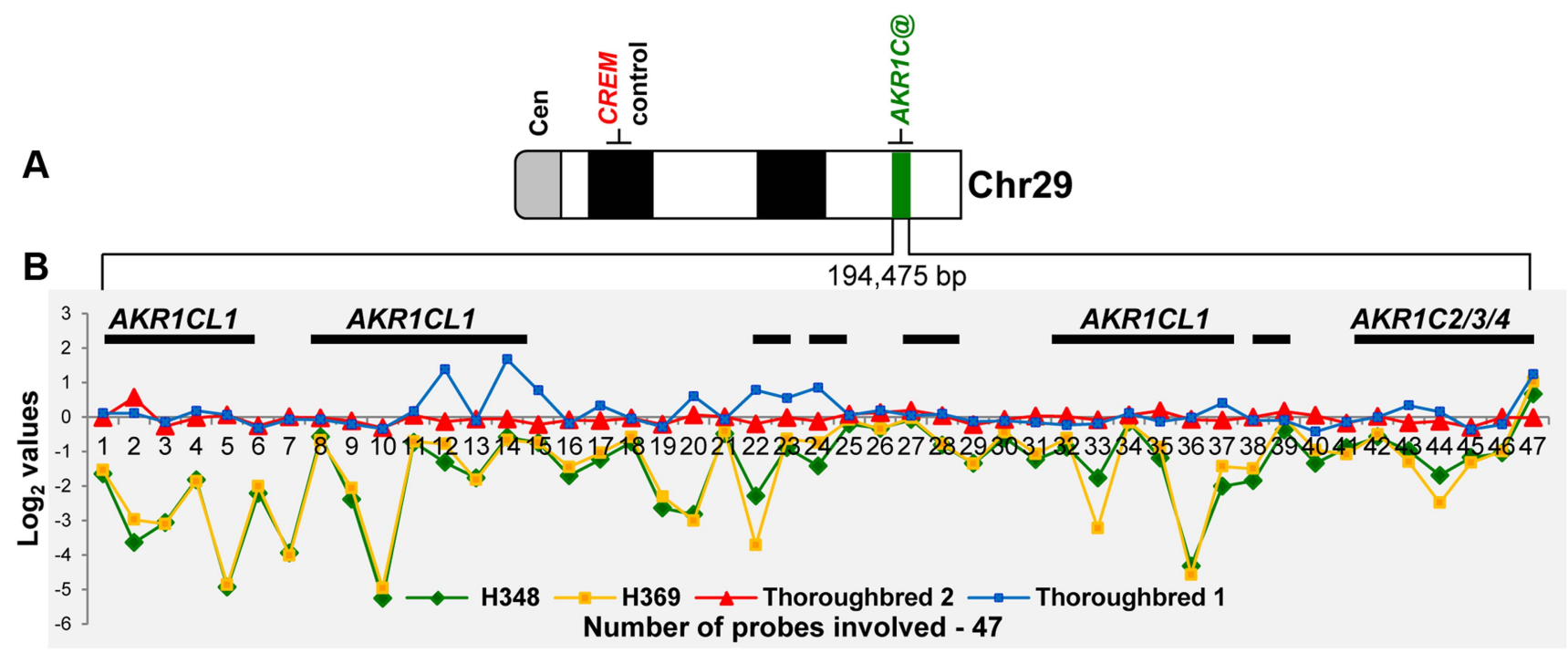

C
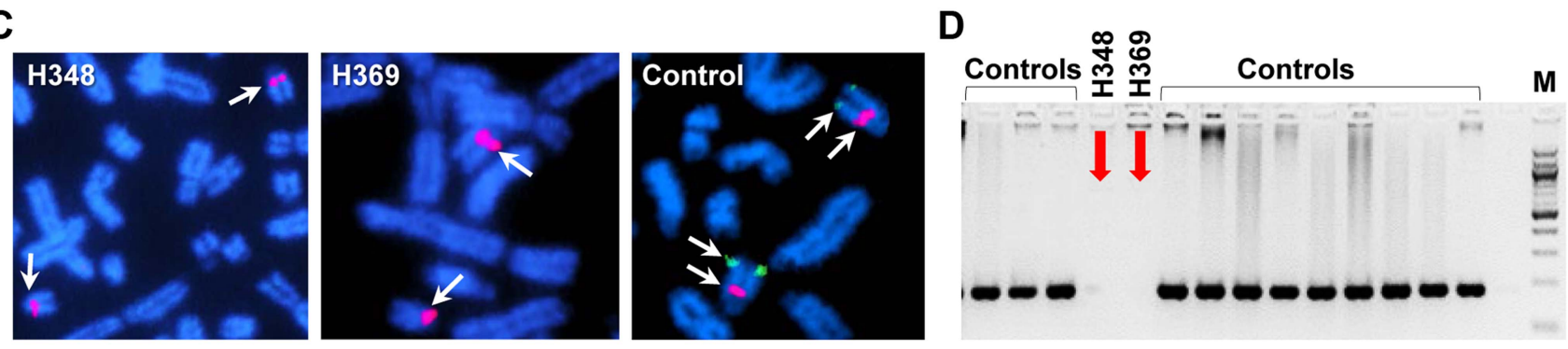

Figure 7. Schematic of the homozygous deletion in chr29, 28.6-28.8 Mb in two XY DSD horses. A. chr29 ideogram showing the location of AKR1C genes and a control gene CREM; B. Detailed map of the CNVR showing the location of genes (black horizontal bars) and CGH signal log2 values for 47 array probes in XY DSD and control horses; C. FISH results with a BAC 23N13 spanning the deletion (green signal) and a control BAC 76H13 for CREM from a non-CNVR (red signal); D. PCR with CNVR-specific primers in XY DSD and control horses. doi:10.1371/journal.pgen.1004712.g007

features of the GNV profile in horses. Copy number variants account for about 1 to $3 \%$ of the horse genome and there are more $\mathrm{CNV}$ s that involve genes than those located in intergenic regions. Though, the number of intergenic GNVs is possibly deflated because all tiling arrays $[38,39]$, including ours, have been biased towards probes for gene exons. For example, $20 \%$ of the probes in the Texas-Adelaide WG array represent protein coding genes, whereas these genes make up only about $2-3 \%$ of the mammalian genome. Notably, all studies find chr12 as the most CNV-enriched (Table 6) and not because of many CNVs, but because of a few very large clusters of olfactory receptors and immunity-related genes (Tables S8, S10).

\section{Copy number variants and segmental duplications}

Studies in human [3,60], dogs [8] and cattle [30] have noted strong correlation between CNVs and segmental duplications (SDs). This is because SDs share 90\% sequence similarity with another genomic location and can promote CNV formation by non-allelic homologous recombination [61]. Similar tendency has been observed in horses [39], although horse SDs are relatively small (largest $\sim 60 \mathrm{~kb}$ ) and comprise only about $0.5-0.6 \%$ of the genome [56], thus less than the portion involved in CNVs (Table 6). Low level of SDs or low copy number repeats was also reported by a recent de novo analysis of the equine genome where no novel classes or types of interspersed repeats were identified [62]. An additional $0.4 \%$ of SDs are in unplaced contigs (chrUn) [56], though in this study only $0.04 \%$ of chrUn sequences had
CNVs (Table 2). Likewise, chr25 which is the most SD-rich chromosome $(1.7 \%)$ according to EquCab2 genome assembly [56], was only moderately enriched with GNVs $(0.35 \%)$ in this study. Yet, findings by us and others support the correlation between CNVs and SDs in some genomic regions. For example, a known large $(750 \mathrm{~kb})$ segmental duplication at the boundary of ELA class I and class III [63] falls into a large common CNVR in chr20:30,127,886-31,231,182 (Table S10); further, low copy number directional repeats have been associated with large deletions in the horse Y chromosome [44] or, GO categories, such as olfactory reception and immune response, prevail among the genes involved both in CNVs and SDs [52]. Therefore, for improved understanding of the genomic architecture of CNVs and their relation to genes and phenotypes in horses, it would be worthwhile to focus future $\mathrm{CNV}$ research on associations between GNVs and SDs, as recently successfully done in dogs [8].

\section{Copy number variable genes and intergenic regions}

It is noteworthy that regardless of the discovery methodology and study cohorts, functional groups of genes that are most affected by GNVs remain the same in all studies. These include genes for transmembrane signal transduction and chemo-attractant sensory perception (olfactory and non-olfactory G-protein coupled receptors, GPCRs), immune response (immunoglobulins, T-cell receptors, MHC protein complexes), and steroid metabolism (Table S9). Not coincidentally, GNVs are associated with the same groups of genes in humans [3,64], cattle/ruminants 
Table 6. Summary statistics of all CNV studies in horses.

\begin{tabular}{|c|c|c|c|c|c|c|}
\hline & This study & Doan et al. 2012a & $\begin{array}{l}\text { Doan et al. } \\
2012 b\end{array}$ & $\begin{array}{l}\text { Dupuis et al. } \\
2012\end{array}$ & $\begin{array}{l}\text { Metzger et al. } \\
2013\end{array}$ & Wang et al. 2014 \\
\hline Platform & Tiling array & Tiling array & $\mathrm{n} / \mathrm{a}$ & SNP Beadchip & SNP Beadchip & Tiling array \\
\hline Production company & Agilent & Agilent & $\mathrm{n} / \mathrm{a}$ & Illumina & Illumina & Nimblegen \\
\hline Genome coverage & WG & Exons and UTRs & WG & WG & WG & WG \\
\hline No of probes & $400 \mathrm{~K}$ & $400 \mathrm{~K}$ & $\mathrm{n} / \mathrm{a}$ & $50 \mathrm{~K}$ & $50 \mathrm{~K}$ & $1.3 \mathrm{M}$ \\
\hline Method & $\mathrm{CGH}$ & $\mathrm{CGH}$ & NGS & SNP genotyping & SNP genotyping & $\mathrm{CGH}$ \\
\hline Breeds & 16 & 15 & 1 & $4^{* *}$ & 17 & 6 \\
\hline Horses & 38 & 16 & 1 & 477 & 717 & 6 \\
\hline $\begin{array}{l}\text { CNV calling } \\
\text { algorithm }\end{array}$ & ADM-2 & ADM-2 & $\begin{array}{l}\text { Control-FREE } \\
\text { copy number } \\
\text { (FREEC) }\end{array}$ & PennCNV [99] & $\begin{array}{l}\text { 1) CNVPartition } \\
\text { (Illumina); 2) PennCNV } \\
\text { [99]; 3) QuantisNP [100] }\end{array}$ & segMNT \\
\hline $\begin{array}{l}\text { CNV calling } \\
\text { threshold }\end{array}$ & $\log _{2} \pm 0.5,5$ probes & $\log _{2} \pm 0.5,3$ probes & $\begin{array}{l}\text { Breakpoint } \\
\text { at }-0.0013 ; \\
\text { a coefficient of } \\
\text { variation } 0.045\end{array}$ & PennCNV [99] & $* * *$ & $\log _{2} \pm 0.5,5$ probes \\
\hline $\begin{array}{l}\text { No of CNVs per } \\
\text { animal }\end{array}$ & 12 to 59 & 55 to 347 & 282 & $\mathrm{n} / \mathrm{a}$ & $\operatorname{Min} 1, \max n / a$ & 22 to 84 \\
\hline No of CNVs/CNVRs* & 258 & 775 & 282 & 478 & $166-1090$ & 353 \\
\hline Gains & 64 & 398 & 274 & 238 & $\mathrm{n} / \mathrm{a}$ & 109 \\
\hline Losses & 172 & 315 & 8 & 236 & $\mathrm{n} / \mathrm{a}$ & 234 \\
\hline Complex & 22 & 62 & $\mathrm{n} / \mathrm{a}$ & $\mathrm{n} / \mathrm{a}$ & $\mathrm{n} / \mathrm{a}$ & $n / a$ \\
\hline CNV size range & $1 \mathrm{~kb}-2.5 \mathrm{Mb}$ & $197 \mathrm{bp}-3.5 \mathrm{Mb}$ & 3.7 kb-4.8 Mb & $97 \mathrm{bp}-2.7 \mathrm{Mb}$ & $516 \mathrm{bp}-0.9 \mathrm{Mb}^{* *}$ & $6.1 \mathrm{~kb}-0.5 \mathrm{Mb}$ \\
\hline CNV size, mean, kb & 110 & 5.3 & $\mathrm{n} / \mathrm{a}$ & 114 & 487 & 38.5 \\
\hline $\begin{array}{l}\text { CNV size, } \\
\text { median, kb }\end{array}$ & 46 & 99.4 & $\mathrm{n} / \mathrm{a}$ & 61 & 169 & 13.1 \\
\hline $\begin{array}{l}\text { Genomic } \\
\text { distribution of CNVs }\end{array}$ & Autosomes, X, Un & Autosomes, $\mathrm{X}$ & Autosomes & Autosomes & Autosomes & $\begin{array}{l}\text { Autosomes, except } \\
\text { chr30, } 31\end{array}$ \\
\hline Most enriched chr. & 12 & 12 & 12 & 12 & 12 & 12 \\
\hline $\begin{array}{l}\text { Chrs. with the } \\
\text { highest no. of CNVs }\end{array}$ & $1 ; 20$ & $1 ; 7$ & $30 ; 31$ & 1 & 12 & 20 \\
\hline $\begin{array}{l}\text { Genome } \\
\text { enrichment \% }\end{array}$ & 1.15 & 3.65 & 3.53 & 2.32 & $1.7-22.0^{* *}$ & 0.61 \\
\hline
\end{tabular}

*As reported by original studies and before consolidating overlapping and tandemly located CNVRs into a composite dataset.

**Dupuis and colleagues specified only large groups of horses (warmblood, coldblood, draft, pony) but not individual breeds.

***Results by Metzger and colleagues vary between different analysis software packages used.

doi:10.1371/journal.pgen.1004712.t006

[30,65,66], pigs [31], dogs [32] and even chicken [67], suggesting the importance of inter-individual variation in these genes for adaptive plasticity [68]. Indeed, genetic diversity and fine functional tuning of sensory receptors, immunoglobulins, natural killer and Toll-like receptors is further enhanced by additional mechanisms, such as asynchronous replication which increases the rate of tandem duplications, and monoallelic expression, so that each sensory neuron or lymphoid cell expresses only one allele of a gene $[69,70]$. Conserved linkage between distinct olfactory receptor genes and the $\mathrm{MHC}$ in several mammalian species suggests their concerted function - in this case, MHC-influenced mate choice in reproduction [71]. Olfactory receptors are also thought to function as chemo-sensing receptors to regulate sperm density, motility, acrosome reaction and sperm-egg interaction in fertilization [71,72]. Thus functionally, the GNV-enriched genes in horses and other mammals fall into just three large categories: sensory perception, immunity and reproduction.

Among the 258 CNVRs detected in this study, 20\% were located in intergenic regions. These CNVRs were relatively small (average $50 \mathrm{~kb}$, median $35 \mathrm{~kb}$ ) and represented predominantly losses (Fig. 2, Table S8). Prevalence of losses among intergenic CNVRs has also been found in dogs [32]. Although there is no information about possible implication of these regions on the function of genes in animal genomes, studies in humans show that intergenic deletions are significantly enriched among gene expression-associated CNVs [73]. Thus, with the improvement of genome sequence assembly and annotation in horses, intergenic GNVRs will be of interest for future studies. We also anticipate that as gene models are revised and converge more with the underlying reality of the genes, some intergenic CNVRs may become genic and vice versa.

\section{Breed-specific CNVs}

One of the goals of CNV research in horses is to find variants that distinguish between breeds or groups of breeds and could be associated with specific adaptations and phenotypic traits of interest. In order to visualize the breeds and the degree of diversity represented in this and previous studies, we performed a phylogenetic analysis using population data of 15 microsatellite loci [74] for the breeds involved (E.G. Cothran, unpublished). The 


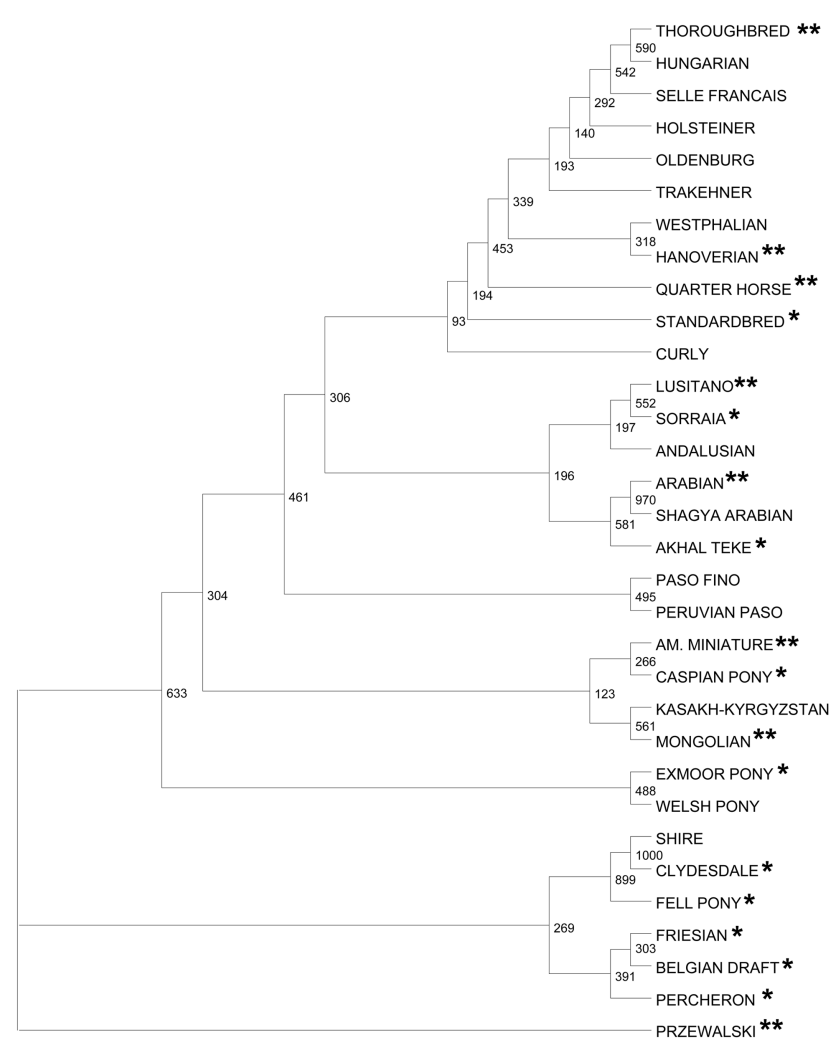

Figure 8. Genetic relationships of horse breeds studied for CNVs. A Maximum Likelihood tree showing genetic relationships of the horse breeds that have been studied for CNVs; ${ }^{*}$ new breeds added in this study (except Swiss Warmblood);** breeds involved in 2 or more studies. Numbers denote bootstrap values.

doi:10.1371/journal.pgen.1004712.g008

dendrogram in Figure 8 shows that while the major clades of domestic horses are represented, there is a clear preponderance of the breeds with Thoroughbred ancestry. It is therefore noteworthy that data for 11 new breeds, mainly representing native ponies and draft horses, were added in this study. Nevertheless, the current tally of horse breeds studied for CNVs is 41 (Table S12) which is less than $10 \%$ of the over 400 horse breeds known worldwide [75]. Furthermore, given that just 7 breeds have been involved in 2 or more studies (Fig. 8, Table S12) and several breeds are represented by one individual $[38,39]$, any CNV reported to be breedspecific should be taken with caution. For example, our composite CNV dataset (Table S10) shows that the 18 CNVs reported to be specific for Hanoverians [37] are present in other breeds. Likewise, only one (chr13: 1,497,390.00-1,508,926.00; EIF2AK1) of the 7 plateau-breed-specific GNVs in heme binding genes [38] is not found in other breeds. The same happened with our data where initially we identified over 10 putative breed-specific CNVs which, after comparison, reduced to 2 - one in Exmoor pony, another in Swiss Warmblood horse (Table S4). Interestingly, no unique CNVs were found in the Przewalski horse which shared similarity mainly with ponies and draft breeds (Table S3). Besides, only 9 of the $25 \mathrm{CNVs}$ in Przewalski horses were shared between the two individuals studied. Similar tendency for intra-breed individual variation was observed for domestic horses where private CNVs predominated over the shared ones. Nevertheless, as suggested by other studies in horses [39], cattle [29], pigs [31] and dogs [33],we anticipate that a small percentage of CNVs might remain unique to their respective breeds, though this requires analysis of much larger and more diverse equine populations. On the other hand, most horse breeds are of recent origin with a good deal of crossbreeding until closed breeds were established which has led to a high degree of haplotype sharing [56,76], and thereby decreased chances for finding breed-specific CNVRs compared to species like dogs [34].

\section{CNVs and disorders of sexual development}

Probably the most exciting goal of GNV research in any species is the discovery of pathogenic variants responsible for complex diseases and congenital disorders. Among these, disorders of sexual development (DSDs) are not uncommon in horses, though causative mutations have been identified for just a few: Y chromosome deletions in $S R Y$-negative $\mathrm{XY}$ sex reversal mares [44] and a point mutation in the androgen receptor gene in 3 related $S R Y$-positive $\mathrm{XY}$ mares [77].

Here, we conducted the first pilot GNV analysis in horses with XY DSD and identified a large autosomal (chr29) deletion in 2 related American Standardbreds (H348 and H369, Table 4). The animals were classified as male pseudo-hermaphrodites with XY male genotype, immature testes-like abdominal gonads, and female-like external phenotype (Table 4). The deletion in chr29:28.6-28.8 Mb was homozygous as confirmed by FISH and PCR, and involved at least 8 genes of which 4 belonged to the aldo-keto reductase family 1 , member $\mathrm{C}$ (AKR1C; Fig. 7). Annotation of these genes in the equine genome is, as yet, preliminary and based on the alignment with human AKR1C proteins in the UCSC Genome Browser (http://genome.ucsc. edu/index.html) and mammalian homology in Ensembl (http:// www.ensembl.org/index.html). Therefore in Fig. 7, three genes are denoted as AKR1CL1 and one gene has three labels, corresponding to $A K R 1 C 2$ in chimpanzee, $A K R 1 C 3$ in human, and $A K R 1 C 4$ in cattle.

The $A K R 1 C$ genes are members of the aldo-keto reductases (AKR) superfamily [78] and encode for $3 \alpha$-hydroxysteroid dehydrogenases [78] which are critically involved in steroid hormone metabolism [79]. In the human genome, there are 4 family members - AKR1C1, ALR1C2, AKR1C3 and AKR1C4, which share $86 \%$ sequence identity and are clustered in HSA10p15-p14 [78,79]. The human $A K R 1 C$ genes are not widely expressed: $A K R 1 C 1$ in brain, kidney, liver and testis, $A K R 1 C 2$ in prostate and brain, $A K R 1 C 3$ in prostate and mammary gland, and $A K R 1 C 4$ in liver, whereas the rat has a single $A K R 1 C$ gene expressed in liver_[79,80,81]. Among other functions, the $A K R 1 C$ genes are involved in the biochemical pathway that leads to dihydrotestosterone (DHT) synthesis without testosterone intermediate. As opposed to 'classical' DHT synthesis from cholesterol and testosterone, this pathway is known as 'the backdoor pathway' and was originally discovered in marsupials [82] and thereafter in eutherian mammals $[45,46,83,84]$. The importance of the 'backdoor pathway' and $A K R 1 C$ genes in male sexual development was recently demonstrated by a study in humans showing that mutations in AKR1C2 and AKR1C4 genes cause abnormal virilization and disordered sexual development, including XY sex reversal [46,84]. Even though no mouse knockout models are available for any of the AKR1C genes (MGI; http://www. informatics.jax.org/), it is tempting to speculate that the homozygous deletion in horse chr29 is a causative or a risk factor for some forms of equine XY DSDs, such as male-pseudohermaphroditism, as observed in this study. It is also worth mentioning that a CNV analysis of human XY DSDs detected a clinically significant de novo $64 \mathrm{~kb}$ duplication in HSA10p14 [28] - a genomic segment next to the $A K R 1 C$ gene cluster (UCSC: http:// genome.ucsc.edu/cgi-bin/hgGateway). Whether this is a coinci- 
dence or the region includes more copy number variable factors contributing to DSDs, needs further investigation. [45,46,84] [84] [28].

Our findings in horses might be of even broader interest because the two deletion carrying horses were elite American Standardbred pacers, Martha Maxine and Arizona Helen (Table 4), whose problematic sexual identity has become public, making headlines in The New York Times [85] and The Horse [86]. Thus, studies are underway to precisely determine the deletion breakpoints and develop molecular tests for detecting other horses with a similar deletion, as well as heterozygous carriers. Finally, the fact that only 2 XY DSD horses out of 6 had this mutation underscores the phenotypic and genetic heterogeneity of these disorders.

\section{Concluding statement}

This study represents an important contribution to GNV research in horses by identifying new $\mathrm{CNV}$ s and developing an integrated datset of 1476 CNVRs to facilitate the discovery of variants of biomedical importance. However, despite progress, the majority of the CNVRs reported for the horse require proper validation by methodologically comparable studies invloving more diverse breeds and individual animals. Last but not least, due to the very nature of CNVs, these regions are likely to have sequence assemblies not as accurate as non-variable regions. Thus, the findings also identified potential targets for genome re-sequencing and -assembly.

\section{Materials and Methods}

\section{Ethics statement}

Procurement of peripheral blood and hair was performed according to the United States Government Principles for the Utilization and Care of Vertebrate Animals Used in Testing, Research and Training. These protocols were approved by Texas A\&M Office of Research Compliance and Biosafety as AUP2009115, AUP2012-0250. CRRC09-32 and CRRC09-47.

\section{Array design}

A horse WG tiling array was designed using the horse genome draft sequence (EquCab2, http://www.ncbi.nlm.nih.gov/ assembly/286598; [56], Oligowiz2.0 (http://www.cbs. dtu.dk/ services/OligoWiz/), ArrayOligoSelector (http://arrayoligosel. sourceforge.net/), and ArrayDesign [87] software packages. The array comprised 417,377 60-mer oligonucleotide probes: 85,852 probes corresponded to one or more exons of the 18,763 annotated equine genes (http://www.ncbi.nlm.nih.gov/genome/ genomes/145?); 305,416 probes originated from intergenic regions (excluding sub-telomeres); 5,716 probes were designed from subtelomeres (the terminal $1 \mathrm{Mb}$ of each chromosome), and 519 probes represented the horse $\mathrm{Y}$ chromosome [58]; our unpublished data). [87]For intergenic probes, including chrUn, repeatmasked (http://www.repeatmasker.org/) sequences were used. For reference genes, we first designed probes from exons. If these were not specific, attempts were made to design probes from introns and upstream/downstream flanking regions of those genes. Before inclusion in the array, the specificity of all sequences were analysed with BLAT (http://www.kentinformatics.com/) and BLAST (http://blast.ncbi.nlm.nih.gov/Blast.cgi) against the EquCab2 reference genome sequence. Probes with more than one hit in the genome were discarded. Possible cross-hybridization of the probes was further evaluated using Kane's parameters [88] and all probes that had a total percent identity $>75-80 \%$ with a nontarget sequence, or probes with contiguous stretches of identity $>$ 15 nucleotides with a non-target sequence were discarded. Only probes with high specificity were kept in the final array. A Cytoband file was generated to align the horse draft sequence assembly with the cytogenetic map [89]. The array, designated as the Texas-Adelaide horse WG tiling array, was fabricated by Agilent Technologies using Agilent SurePrint G3 technology and $2 \times 400 \mathrm{~K}$ chip format (two arrays on a single slide). The array is available at Agilent Technologies; Design ID \#030025, Cat. No G4124A.

\section{Horses, breeds, phenotypes}

The GNV discovery cohort comprised 38 horses representing 16 diverse breeds and the Przewalski's horse (Table S1). Horse breeds were selected according to the recent population studies $[51,56,76,90]$ with an aim to maximize the genetic diversity among samples and to encompass the common warm blood, cold blood (draft) and native pony breeds. An additional cohort of 52 normal horses representing the same 16 breeds was used for quantitative PCR validation of CNVs. Finally, a pilot study testing the utility of the tiling array for the discovery of GNVs contributing to equine congenital disorders used 6 horses previously diagnosed with XY disorders of sexual development (XY DSDs; Table 4) [44].

\section{DNA isolation}

Genomic DNA was isolated from peripheral blood or hair follicles using QIAGEN Gentra PureGene Blood kit (Qiagen) according to manufacturer's protocol. The DNA was cleaned with DNeasy Blood and Tissue kit (Qiagen) and quality checked by gel electrophoresis and by Nanodrop spectrophotometry (Thermo Scientific).

\section{Array comparative genomic hybridization}

Probe labeling and array CGH experiments were performed according to Agilent Technologies Protocol Version 7.3, March 2014 (http://www.chem.agilent.com/Library/usermanuals/ Public/G4410-90010_GGH_Enzymatic_7.3.pdf). All hybridizations comprised of a pair of differently labeled probes, one of which was always the reference DNA - a Thoroughbred mare Twilight for females and a Thoroughbred stallion Bravo for males (see explanations below). The genomic DNA (gDNA) was cleaved to 200-500 bp fragments with RsaI and AluI (Promega) and labeled with Cy3 (the reference DNA) or Cy5 (sample DNA) by random priming using Genomic DNA Enzymatic Labeling Kit (Agilent Technologies). The products were cleaned with $30 \mathrm{kDa}$ filters (Amicon) and the yield and specific activity of labeled DNA was determined with a Nanodrop spectrophotometer. Typical yield for $1 \mu \mathrm{g}$ of starting DNA was 6-8 $\mu \mathrm{g}$; specific activity for Cy3 was 25-40 pmol/ $\mu \mathrm{g}$ and for Cy5 20-35 pmol/ $\mu \mathrm{g}$. The hybridization mixture was prepared using Agilent Oligo aCGH Hybridization Kit and contained equal quantity of Cy3 and Cy5 labeled probes, $1 \mu \mathrm{g} / \mu \mathrm{L}$ horse Cotl DNA, $10 \times$ blocking agent, and $2 \times$ Hi-RPM buffer. Denatured and pre-annealed probe mixture was applied onto gasket slide, placed in Agilent SureHyb hybridization chamber, 'sandwiched' with an array slide and incubated in Agilent hybridization oven at $65^{\circ} \mathrm{C}$ for 40 hours. The array slides were washed with Agilent aCGH Wash Buffers 1 and 2 and dried with Acetonitrile and Stabilization and Drying Solutions (Agilent Technologies).

\section{Array CGH data analysis}

The slides were scanned with Agilent SureScan DNA Microarray Scanner and Scanner Control software v8.3. The data were extracted and normalized with Agilent Feature Extraction 
software v10.10.1.1 and saved in.fep format. The Feature Extraction software also checks the quality of aCGH by measuring Derivative $\log _{2}$ Ratio Standard Deviation (DLRSD), Signal-ToNoise Ratio (SNR) and Background Noise (BGNoise). The data were analyzed with Agilent Genomic Workbench 5.0 software. In each array spot $\log _{2}$ ratios of Cy3 versus Cy5 were computed with the default $P$-value threshold 0.05 and overlap threshold value 0.9 . The GNVs were represented by gains and losses of normalized fluorescence intensities relative to the reference and called by conservative criteria which required alterations of $>0.5 \log _{2}$ ratios over 5 neighboring probes. Homozygous losses were called when signal $\log _{2}$ ratio was $<-2.0$. Copy number variable regions (CNVRs) were determined by ADM-2 algorithm [91] by combining overlapping and adjacent CNVs in all samples across the CGH experiments. Output files were generated with genomic coordinates and cytoband locations for all CNVs. The raw data were submitted to NCBI Gene Expression Omnibus (GEO) accession GSE55266.

\section{Array performance evaluation}

To evaluate baseline variations and determine FDR [92,93] female and male self-to-self, and female-to-male control hybridizations were conducted using blood DNA from one female and one male Thoroughbred horses. The female Thoroughbred, Twilight, was the DNA donor for the horse reference sequence EquCab2 [56] and the origin of the probes on the tiling array. The male Thoroughbred, Bravo, a half-sibling to Twilight, was the DNA donor for the CHORI-241 BAC library (http://bacpac. chori.org/equine241.htm) and the origin of all $\mathrm{Y}$ chromosome probes on the array. The FDR was calculated as a percentage of the ratio of CNVs in self-to-self hybridization to the total number of CNVs in all experiments. Additionally, array performance was evaluated by self-to-self hybridizations with blood and hair DNA from one Quarter Horse (H528, Table S1). Hybridization quality was assessed by DLRSD which calculates probe-to probe log ratio noise of an array; (http://www.chem.agilent.com/Library/ applications/5989-6624EN.pdf): DLRSD <0.2 was considered excellent; $0.2 \geq \mathrm{DLRSD} \leq 0.3$ was good, and values $>0.3$ indicated poor quality hybridization.

\section{Chromosome CNVR enrichment}

Horse chromosome enrichment percentage was determined by the total length of CNVRs present in each chromosome, divided by chromosome length (Ensembl, http://www.ensembl.org/ index.html).

\section{Gene ontology enrichment analysis}

Ensembl gene list (Ensembl Genebuild 73.2) along with their position in the horse genome was added to Agilent Genomic Workbench as a custom track to determine the genic and intergenic CNVs. Gene Ontology analysis (GO) and Kyoto Encyclopedia of Genes and Genomes (KEGG) pathway analysis of the genes present in CNVs were performed using DAVID bioinformatics tool with default settings $[94,95]$. Because only a limited number of genes in the horse genome have been annotated, horse gene IDs were converted to orthologous human Ensembl gene IDs by BioMart, followed by GO and pathway analyses, as described above. Biological functions of the genes in CNVRs were further analyzed manually by data mining in Ensembl (http://www.ensembl.org/index.html), UCSG (http:// genome.ucsc.edu/) and NCBI (http://www.ncbi.nlm.nih.gov/) Genome Browsers searching for data for equine orthologs in other mammalian species. CNVs present in intergenic regions were analyzed in UCSC genome browser and NCBI and
GeneCards (http://www.genecards.org/) for similarities to known mammalian genes.

A composite CNV dataset for the horse (Table S10) was generated by aligning genomic positions of CNVs/CNVRs from this and all previously published studies [35,36,37,38,39]. Partially or completely overlapping and adjacent CNVs (the end position of a previous CNV and the start position of the next CNV are the same) were consolidated into one GNVR.

\section{Array CGH data validation by qualitative and quantitative PCR}

Genomic copy number changes as detected by aCGH were validated by quantitative PCR (qPCR) for 18 selected CNVRs using 22 probe-specific primers. Additionally, 8 putative homozygous deletions were validated by regular (qualitative) PCR. Primers (Table S2) were designed inside CNVRs using array probe sequences and the horse whole genome sequence information (EquCab2 at UCSC: http://genome.ucsc.edu/and Ensembl: http://www.ensembl.org/index.html) and Primer3 software (http://bioinfo.ut.ee/primer3-0.4.0/primer3/input. $\mathrm{htm})$. The qPCR experiments were performed with LightCycler 480 (Roche Diagnostics) in triplicate assays. Each assay was done in triplicate $20 \mu \mathrm{L}$ reactions containing $50 \mathrm{ng}$ of template DNA, $10 \mu \mathrm{M}$ primers and the SYBR Green PGR kit (Roche). Relative copy numbers of the selected regions were determined in comparison to the reference sample (Thoroughbred and Quarter Horse) and normalized to an autosomal reference gene GAPDH. The cycling conditions were 1 cycle $5 \mathrm{~min}$ at $95^{\circ} \mathrm{C} ; 45$ cycles $10 \mathrm{sec}$ at $95^{\circ} \mathrm{C}, 5 \mathrm{sec}$ at $58^{\circ} \mathrm{C}$, and $10 \mathrm{sec}$ at $72^{\circ} \mathrm{C} ; 1$ cycle for melting curve $30 \sec 95^{\circ} \mathrm{C}, 30 \sec 65^{\circ} \mathrm{C}$ and final cooling $20 \mathrm{sec}$ at $50^{\circ} \mathrm{C}$. Quantification of the copy number was carried out using the comparative $\mathrm{C}_{\mathrm{T}}$ method $\left(2^{\Delta \Delta} \mathrm{Ct}\right)[96,97]$ with $\mathrm{p}<$ 0.05 as a cut-off threshold for statistical significance. Qualitative PCR results were analyzed by agarose gel electrophoresis.

\section{Array CGH data validation by fluorescence in situ hybridization (FISH)}

GNV specific primers were used to screen CHORI-241 BAC library (http://bacpac.chori.org/equine241.htm) by PCR (Table S2); BAC DNA was isolated by Plasmid Midiprep kit (Qiagen), labeled with biotin-16-dUTP or digoxigenin-11-dUTP using Biotin- or DIG-Nick Translation Mix (Roche), and hybridized to metaphase chromosomes of CNV carriers and control horses following standard protocols [98]. A BAC clone representing a non-CNV region was used as a control in each FISH experiment. Images for a minimum of 20 metaphase and/or interphase cells were captured for each experiment and analyzed with a Zeiss Axioplan2 fluorescent microscope equipped with Isis v5.2 (MetaSystems $\mathrm{GmbH}$ ) software.

\section{Phylogenetic analysis}

Genotypes for 15 microsatellite loci [74]; E.G. Cothran, unpublished) were available for 32 out of 41 horse breeds involved in CNV studies (see Table S12). Majority-rule consensus of Restricted Maximum Likelihood (RML) trees were constructed and visualized as described elsewhere [74]. The Przewalski Horse population was used as an out-group.

\section{Supporting Information}

Figure S1 Array and aCGH quality control. A. Genome-wide distribution of CNVs in self-to-self hybridization (upper) compared to cumulative hybridizations with all animals (lower) to determine FDR; green vertical lines denote CNVs; B. Male-to-female aCGH 
results for the X chromosome; $\mathbf{C}$. DLRSD values of aCGH using DNA from blood (left) and from hair (right) of the same individual. (PDF)

Figure S2 Homozygous deletions. Confirmation of putative homozygous deletion CNVs (red arrows) by qualitative PCR. (PDF)

Figure S3 Validation of selected GNVRs by quantitative PGR (qPCR). A1-A14 qPCR was in agreement with aCGH in discovery horses and their breed-mates; B1-B3 qPCR agrees with aCGH in the discovery horse (left) but not in additional horses of the same breed (right).

(PDF)

Figure S4 Validation of a copy number gain in $\operatorname{chr} 1(114.0 \mathrm{Mb})$ by FISH. A. and B. - metaphase and interphase of the Thoroughbred control; G. and D. metaphase and interphase of a Quarter Horse; red signals - BAC 132B13; green signals in D. a single-copy control BAC. Note the difference in copy numbers between homologous chromosomes in both horses.

(PDF)

Table S1 Horse breeds $(\mathrm{n}=16)$ and individuals $(\mathrm{n}=38)$ used in this study.

(XLSX)

Table S2 Primers for quantitative and qualitative PCR to validate GNVs.

(XLSX)

Table S3 List of all 950 CNV calls in the study cohort. (XLSX)

Table S4 Tentative breed-specific CNVRs.

(XLSX)

Table S5 258 GNVRs identified in the horse genome in this study.

(XLSX)

\section{References}

1. Ohno S (1970) Evolution by gene duplication. New York: Springer-Verlag.150 pp.

2. Iafrate AJ, Feuk L, Rivera MN, Listewnik ML, Donahoe PK, et al. (2004) Detection of large-scale variation in the human genome. Nat Genet 36: $949-$ 951.

3. Redon R, Ishikawa S, Fitch KR, Feuk L, Perry GH, et al. (2006) Global variation in copy number in the human genome. Nature 444: 444-454

4. Li J, Jiang T, Mao JH, Balmain A, Peterson L, et al. (2004) Genomic segmental polymorphisms in inbred mouse strains. Nat Genet 36: 952-954.

5. Griffin DK, Robertson LB, Tempest HG, Vignal A, Fillon V, et al. (2008) Whole genome comparative studies between chicken and turkey and their implications for avian genome evolution. BMC Genomics 9: 168.

6. Liu GE, Hou Y, Zhu B, Cardone MF, Jiang L, et al. (2010) Analysis of copy number variations among diverse cattle breeds. Genome Res 20: 693-703.

7. Alvarez CE, Akey JM (2012) Copy number variation in the domestic dog. Mamm Genome 23: 144-163.

8. Nicholas TJ, Cheng Z, Ventura M, Mealey K, Eichler EE, et al. (2009) The genomic architecture of segmental duplications and associated copy number variants in dogs. Genome Res 19: 491-499.

9. Clop A, Vidal O, Amills M (2012) Copy number variation in the genomes of domestic animals. Animal Genet 43: 503-517.

10. Bickhart DM, Liu GE (2014) The challenges and importance of structural variation detection in livestock. Frontiers in Genetics 5: 37.

11. Weischenfeldt J, Symmons O, Spitz F, Korbel JO (2013) Phenotypic impact of genomic structural variation: insights from and for human disease. Nature Rev Genet 14: 125-138.

12. Conrad DF, Pinto D, Redon R, Feuk L, Gokcumen O, et al. (2010) Origins and functional impact of copy number variation in the human genome. Nature 464: 704-712.

13. Pang AW, MacDonald JR, Pinto D, Wei J, Rafiq MA, et al. (2010) Towards a comprehensive structural variation map of an individual human genome. Genome Biol 11: R52.
Table S6 Gains and losses with high $\log _{2}$ alteration values. (XLSX)

Table S7 Genomic locations, names, symbols and known or predicted functions of copy number variable genes.

(XLSX)

Table S8 Intergenic CNVRs.

(XLSX)

Table S9 GO analysis of equine copy number variable genes. (XLSX)

Table S10 Integrated dataset of $1476 \mathrm{CNV}_{\mathrm{S}} / \mathrm{CNVR}_{\mathrm{s}}$ in the horse.

(XLSX)

Table S11 Details of validation of 19 selected CNVRs by qPCR. (XLSX)

Table S12 List of horse breeds studied for CNVs. (XLSX)

\section{Acknowledgments}

The authors thank Dr. Doug Antzack and Dr. Donald Miller for kindly providing blood samples and fibroblast cell lines for Thoroughbreds Twilight and Bravo, Jana Caldwell for blood samples from a Quarter Horse and a Percheron, Dr. Vincent Gerber for DNA samples from 3 Swiss Warmblood horses, Dr. Molly McGue for DNA samples from 2 American Standardbreds, Dr. Tom A. E. Stout for blood samples from 4 Friesians, and Helena Josefina Kjöllerström for DNA samples from 2 Sorraia horses. We also thank Dr. Scott V. Dindot and Dr. Ryan Doan for valuable advice and discussions regarding array CGH and CNV data analysis, and Agilent Technologies for continuing technical and bioinformatics support.

\section{Author Contributions}

Conceived and designed the experiments: TR BPG DLA ZQ SG. Performed the experiments: SG ZQ PJD EF TR. Analyzed the data: TR SG BPG DLA ZQ EF EGC RJ. Contributed reagents/materials/analysis tools: EGC RJ SM DGK TLL. Wrote the paper: TR SG BPG EGC DLA.

14. Beckmann JS, Sharp AJ, Antonarakis SE (2008) CNVs and genetic medicine (excitement and consequences of a rediscovery). Cytogenet Genome Res 123: 716.

15. Beckmann JS, Estivill X, Antonarakis SE (2007) Copy number variants and genetic traits: closer to the resolution of phenotypic to genotypic variability. Nature Rev Genet 8: 639-646.

16. Cooper GM, Nickerson DA, Eichler EE (2007) Mutational and selective effects on copy-number variants in the human genome. Nat Genet 39: S22-29.

17. Rogers AJ, Chu JH, Darvishi K, Ionita-Laza I, Lehmann H, et al. (2013) Copy number variation prevalence in known asthma genes and their impact on asthma susceptibility. Clin Exp Allergy 43: 455-462.

18. Alvarado DM, Buchan JG, Frick SL, Herzenberg JE, Dobbs MB, et al. (2013) Copy number analysis of 413 isolated talipes equinovarus patients suggests role for transcriptional regulators of early limb development. Eur J Hum Genet 21: 373-380.

19. Robinson JI, Carr IM, Cooper DL, Rashid LH, Martin SG, et al. (2012) Confirmation of association of FCGR3B but not FCGR3A copy number with susceptibility to autoantibody positive rheumatoid arthritis. Hum Mutat 33: 741-749.

20. Peng Y, Chen M, Liu XJ, Liu W, Li Q et al. (2013) The CYP2C19 genotype does not impact the long-term prognosis of patients with coronary artery disease. Atherosclerosis 227: 106-111.

21. Hitz MP, Lemieux-Perreault LP, Marshall C, Feroz-Zada Y, Davies R, et al. (2012) Rare copy number variants contribute to congenital left-sided heart disease. PLoS Genet 8: e1002903.

22. Lupski JR (2007) Genomic rearrangements and sporadic disease. Nat Genet 39: S43-47.

23. Grayton HM, Fernandes C, Rujescu D, Collier DA (2012) Copy number variations in neurodevelopmental disorders. Progress in Neurobiology 99: 81-91.

24. Carrell DT, Aston KI (2011) The search for SNPs, CNVs, and epigenetic variants associated with the complex disease of male infertility. Syst Biol Reprod Med 57: 17-26. 
25. White S, Ohnesorg T, Notini A, Roeszler K, Hewitt J, et al. (2011) Copy number variation in patients with disorders of sex development due to $46, \mathrm{XY}$ gonadal dysgenesis. PLoS One 6: e17793.

26. Tuttelmann F, Simoni M, Kliesch S, Ledig S, Dworniczak B, et al. (2011) Copy number variants in patients with severe oligozoospermia and Sertoli-cell-only syndrome. PLoS One 6: e19426.

27. Ledig S, Ropke A, Wieacker P (2010) Copy number variants in premature ovarian failure and ovarian dysgenesis. Sex Dev 4: 225-232.

28. Tannour-Louet M, Han S, Corbett ST, Louet JF, Yatsenko S, et al. (2010) Identification of de novo copy number variants associated with human disorders of sexual development. PLoS One 5: e15392.

29. Liu GE, Bickhart DM (2012) Copy number variation in the cattle genome. Funct Integr Genomics 12: 609-624.

30. Bickhart DM, Hou Y, Schroeder SG, Alkan C, Cardone MF, et al. (2012) Copy number variation of individual cattle genomes using next-generation sequencing. Genome Res 22: 778-790.

31. Wang J, Jiang J, Wang H, Kang H, Zhang Q, et al. (2014) Enhancing GenomeWide Copy Number Variation Identification by High Density Array CGH Using Diverse Resources of Pig Breeds. PLoS One 9: e87571.

32. Berglund J, Nevalainen EM, Molin AM, Perloski M, Andre C, et al. (2012) Novel origins of copy number variation in the dog genome. Genome Biol 13: R73.

33. Molin AM, Berglund J, Webster MT, Lindblad-Toh K (2014) Genome-wide copy number variant discovery in dogs using the CanineHD genotyping array. BMC Genomics 15: 210 .

34. Nicholas TJ, Baker C, Eichler EE, Akey JM (2011) A high-resolution integrated map of copy number polymorphisms within and between breeds of the modern domesticated dog. BMC Genomics 12: 414.

35. Doan R, Gohen ND, Sawyer J, Ghaffari N, Johnson CD, et al. (2012) WholeGenome Sequencing and Genetic Variant Analysis of a Quarter Horse Mare. BMC Genomics 13: 78 .

36. Dupuis MC, Zhang Z, Durkin K, Charlier C, Lekeux P, et al. (2013) Detection of copy number variants in the horse genome and examination of their association with recurrent laryngeal neuropathy. Animal Genet 44: 206-208.

37. Metzger J, Philipp U, Lopes MS, da Camara Machado A, Felicetti M, et al. (2013) Analysis of copy number variants by three detection algorithms and their association with body size in horses. BMC Genomics 14: 487.

38. Wang W, Wang S, Hou C, Xing Y, Cao J, et al. (2014) Genome-Wide Detection of Copy Number Variations among Diverse Horse Breeds by Array CGH. PLoS One 9: e86860.

39. Doan R, Cohen N, Harrington J, Veazy K, Juras R, et al. (2012) Identification of copy number variants in horses. Genome Res 22: 899-907.

40. Riethman H (2008) Human subtelomeric copy number variations. Cytogenet Genome Res 123: 244-252.

41. Li Y, Mei S, Zhang X, Peng X, Liu G, et al. (2012) Identification of genomewide copy number variations among diverse pig breeds by array CGH. BMC Genomics 13: 725 .

42. Hou Y, Bickhart DM, Chung H, Hutchison JL, Norman HD, et al. (2012) Analysis of copy number variations in Holstein cows identify potential mechanisms contributing to differences in residual feed intake. Funct Integr genomics 12: 717-723

43. Shull AY, Clendenning ML, Ghoshal-Gupta S, Farrell CL, Vangapandu HV, et al. (2013) Somatic mutations, allele loss, and DNA methylation of the Cub and Sushi Multiple Domains 1 (CSMD1) gene reveals association with early age of diagnosis in colorectal cancer patients. PLoS One 8: e58731.

44. Raudsepp T, Durkin K, Lear TL, Das PJ, Avila F, et al. (2010) Molecular heterogeneity of XY sex reversal in horses. Animal Genet 41 Suppl 2: 41-52.

45. Fukami M, Homma K, Hasegawa T, Ogata T (2013) Backdoor pathway for dihydrotestosterone biosynthesis: implications for normal and abnormal human sex development. Dev Dyn: 242: 320-329.

46. Biason-Lauber A, Miller WL, Pandey AV, Fluck CE (2013) Of marsupials and men: "Backdoor" dihydrotestosterone synthesis in male sexual differentiation. Mol Cell Endocrinol 371: 124-132.

47. Raudsepp T, Gustafson-Seabury A, Durkin K, Wagner ML, Goh G, et al. (2008) A 4,103 marker integrated physical and comparative map of the horse genome. Cytogenet Genome Res 122: 28-36.

48. McCarroll SA (2010) Copy number variation and human genome maps. Nat Genet 42: 365-366.

49. Mills RE, Walter K, Stewart C, Handsaker RE, Chen K, et al. (2011) Mapping copy number variation by population-scale genome sequencing. Nature 470 : 59-65.

50. Haraksingh RR, Abyzov A, Gerstein M, Urban AE, Snyder M (2011) Genomewide mapping of copy number variation in humans: comparative analysis of high resolution array platforms. PLoS One 6: e27859.

51. McCue ME, Bannasch DL, Petersen JL, Gurr J, Bailey E, et al. (2012) A high density SNP array for the domestic horse and extant Perissodactyla: utility for association mapping, genetic diversity, and phylogeny studies. PLoS Genet 8: e1002451.

52. Orlando L, Ginolhac A, Zhang G, Froese D, Albrechtsen A, et al. (2013) Recalibrating Equus evolution using the genome sequence of an early Middle Pleistocene horse. Nature 499: 74-78.

53. Skaletsky H, Kuroda-Kawaguchi T, Minx PJ, Cordum HS, Hillier L, et al. (2003) The male-specific region of the human Y chromosome is a mosaic of discrete sequence classes. Nature 423: 825-837.
54. Li G, Davis BW, Raudsepp T, Pearks Wilkerson AJ, Mason VC, et al. (2013) Comparative analysis of mammalian $\mathrm{Y}$ chromosomes illuminates ancestral structure and lineage-specific evolution. Genome Res 23: 1486-1495.

55. DeScipio C, Spinner NB, Kaur M, Yaeger D, Conlin LK, et al. (2008) Finemapping subtelomeric deletions and duplications by comparative genomic hybridization in 42 individuals. Am J Med Genet, Part A 146A: 730-739.

56. Wade CM, Giulotto E, Sigurdsson S, Zoli M, Gnerre S, et al. (2009) Genome sequence, comparative analysis, and population genetics of the domestic horse. Science 326: 865-867.

57. Huddleston J, Ranade S, Malig M, Antonacci F, Chaisson M, et al. (2014) Reconstructing complex regions of genomes using long-read sequencing technology. Genome Res 24: 688-696.

58. Paria N, Raudsepp T, Pearks Wilkerson AJ, O'Brien PC, Ferguson-Smith MA, et al. (2011) A gene catalogue of the euchromatic male-specific region of the horse Y chromosome: comparison with human and other mammals. PLoS One 6: e21374.

59. Wang J, Jiang J, Fu W, Jiang L, Ding X, et al. (2012) A genome-wide detection of copy number variations using SNP genotyping arrays in swine. BMC Genomics 13: 273

60. Du R, Lu C, Jiang Z, Li S, Ma R, et al. (2012) Efficient typing of copy number variations in a segmental duplication-mediated rearrangement hotspot using multiplex competitive amplification. J Hum Genet 57: 545-551.

61. Stankiewicz P, Lupski JR (2010) Structural variation in the human genome and its role in disease. Ann Rev Med 61: 437-455.

62. Adelson DL, Raison JM, Garber M, Edgar RC (2010) Interspersed repeats in the horse (Equus caballus); spatial correlations highlight conserved chromosomal domains. Animal Genet 41 Suppl 2: 91-99.

63. Brinkmeyer-Langford CL, Murphy WJ, Childers CP, Skow LC (2010) A conserved segmental duplication within ELA. Animal Genet 41 Suppl 2: 186195.

64. Hasin Y, Olender T, Khen M, Gonzaga-Jauregui C, Kim PM, et al. (2008) High-resolution copy-number variation map reflects human olfactory receptor diversity and evolution. PLoS Genet 4: e1000249.

65. Fontanesi L, Beretti F, Martelli PL, Colombo M, Dall'olio S, et al. (2011) A first comparative map of copy number variations in the sheep genome. Genomics 97 : 158-165.

66. Fontanesi L, Martelli PL, Beretti F, Riggio V, Dall'Olio S, et al. (2010) An initial comparative map of copy number variations in the goat (Capra hircus) genome. BMC Genomics 11: 639 .

67. Wang X, Nahashon S, Feaster TK, Bohannon-Stewart A, Adefope N (2010) An initial map of chromosomal segmental copy number variations in the chicken. BMC Genomics 11: 351

68. Iskow RC, Gokcumen O, Lee C (2012) Exploring the role of copy number variants in human adaptation. Trends Genet 28: 245-257.

69. Gimelbrant AA, Chess A (2006) An epigenetic state associated with areas of gene duplication. Genome Res 16: 723-729.

70. Hasin-Brumshtein Y, Lancet D, Olender T (2009) Human olfaction: from genomic variation to phenotypic diversity. Trends Genet 25: 178-184.

71. Santos PS, Kellermann T, Uchanska-Ziegler B, Ziegler A (2010) Genomic architecture of MHC-linked odorant receptor gene repertoires among 16 vertebrate species. Immunogenetics 62: 569-584.

72. Fukuda N, Yomogida K, Okabe M, Touhara K (2004) Functional characterization of a mouse testicular olfactory receptor and its role in chemosensing and in regulation of sperm motility. J Cell Sci 117: 5835-5845.

73. Schlattl A, Anders S, Waszak SM, Huber W, Korbel JO (2011) Relating GNVs to transcriptome data at fine resolution: assessment of the effect of variant size, type, and overlap with functional regions. Genome Res 21: 2004-2013.

74. Khanshour A, Conant E, Juras R, Cothran EG (2013) Microsatellite analysis of genetic diversity and population structure of Arabian horse populations. J Hered 104: 386-398.

75. Hendricks B (1995) International Encyclopedia of Horse Breeds. University of Oklahoma Press, Norman, 512 pp.

76. Petersen JL, Mickelson JR, Cothran EG, Andersson LS, Axelsson J, et al. (2013) Genetic diversity in the modern horse illustrated from genome-wide SNP data. PLoS One 8: e54997.

77. Revay T, Villagomez DA, Brewer D, Chenier T, King WA (2012) GTG mutation in the start codon of the androgen receptor gene in a family of horses with 64,XY disorder of sex development. Sex Dev 6: 108-116.

78. Penning TM, Drury JE (2007) Human aldo-keto reductases: Function, gene regulation, and single nucleotide polymorphisms. Arch Biochem Biophys 464: 241-250.

79. Penning TM, Jin Y, Steckelbroeck S, Lanisnik Rizner T, Lewis M (2004) Structure-function of human 3 alpha-hydroxysteroid dehydrogenases: genes and proteins. Mol Cell Endocrinol 215: 63-72.

80. O'Connor T, Ireland LS, Harrison DJ, Hayes JD (1999) Major differences exist in the function and tissue-specific expression of human aflatoxin B1 aldehyde reductase and the principal human aldo-keto reductase AKR1 family members. Biochem J 343 Pt 2: 487-504.

81. Penning TM, Burczynski ME, Jez JM, Hung CF, Lin HK, et al. (2000) Human 3alpha-hydroxysteroid dehydrogenase isoforms (AKR1C1-AKR1C4) of the aldo-keto reductase superfamily: functional plasticity and tissue distribution reveals roles in the inactivation and formation of male and female sex hormones. Biochem J 351: 67-77. 
82. Wilson JD, Auchus RJ, Leihy MW, Guryev OL, Estabrook RW, et al. (2003) 5 alpha-androstane-3alpha,17beta-diol is formed in tammar wallaby pouch young testes by a pathway involving 5alpha-pregnane-3alpha,17alpha-diol-20one as a key intermediate. Endocrinology 144: 575-580.

83. Auchus RJ (2004) The backdoor pathway to dihydrotestosterone. Trends Endocrinol Metab 15: 432-438.

84. Fluck CE, Meyer-Boni M, Pandey AV, Kempna P, Miller WL, et al. (2011) Why boys will be boys: two pathways of fetal testicular androgen biosynthesis are needed for male sexual differentiation. Am J Hum Genet 89: 201-218.

85. Finely B (18 Sept 2009). Another sex dispute, but this athlete has four legs. The New York Times. Available: http://www.nytimes.com/2009/09/19/sports/ 19racing.html.

86. Melsky R (06 Aug 2009). Pacer Arizona Helen Reclassified as "Horse". The Horse.com. Available: http://www.thehorse.com/ViewArticle.aspx?ID=14677.

87. Sudderth AK, Das PJ, Varner DD, Raudsepp T (2010) Determination of optimal semen processing methods for total RNA isolation and sperm genomic analysis. Animal Reprod Sci: S149-S150.

88. Kane MD, Jatkoe TA, Stumpf CR, Lu J, Thomas JD, et al. (2000) Assessment of the sensitivity and specificity of oligonucleotide (50mer) microarrays. Nucleic Acids Res 28: 4552-4557.

89. ISCNH1997, Committee: Bowling AT, Breen, M., Chowdhary, B. P., Hirota, K., Lear, T., Millon, L. V., Ponce de Leon, F. A., Raudsepp, T., Stranzinger, G. (1997) International system for cytogenetic nomenclature of the domestic horse. Report of the Third International Committee for the Standardization of the domestic horse karyotype. Chromosome Res 5: 433-443.

90. Petersen JL, Mickelson JR, Rendahl AK, Valberg SJ, Andersson LS, et al. (2013) Genome-wide analysis reveals selection for important traits in domestic horse breeds. PLoS Genet 9: e1003211.
91. Lipson D, Aumann Y, Ben-Dor A, Linial N, Yakhini Z (2006) Efficient calculation of interval scores for DNA copy number data analysis. J Comput Biol 13: 215-228.

92. Wang P, Kim Y, Pollack J, Narasimhan B, Tibshirani R (2005) A method for calling gains and losses in array CGH data. Biostatistics 6: 45-58.

93. Benjamini Y, Hochberg Y (1995) Controlling the false discovery rate: a practical and powerful approach to multiple testing. J Roy Statist Soc Ser B (Methodological): 289-300.

94. Huang da W, Sherman BT, Lempicki RA (2009) Systematic and integrative analysis of large gene lists using DAVID bioinformatics resources. Nat Protoc 4: $44-57$.

95. Huang da W, Sherman BT, Lempicki RA (2009) Bioinformatics enrichment tools: paths toward the comprehensive functional analysis of large gene lists. Nucleic Acids Res 37: 1-13.

96. Bodin L, Beaune PH, Loriot MA (2005) Determination of cytochrome P450 2D6 (CYP2D6) gene copy number by real-time quantitative PCR. J Biomed Biotechnol 2005: 248-253.

97. Livak KJ, Schmittgen TD (2001) Analysis of relative gene expression data using real-time quantitative PCR and the 2(-Delta Delta C(T)) method. Methods 25: 402-408.

98. Raudsepp T, Chowdhary BP (2008) FISH for mapping single copy genes. Methods Mol Biol 422: 31-49.

99. Wang K, Li M, Hadley D, Liu R, Glessner J, et al. (2007) PennCNV: an integrated hidden Markov model designed for high-resolution copy number variation detection in whole-genome SNP genotyping data. Genome Res 17: $1665-1674$

100. Colella S, Yau C, Taylor JM, Mirza G, Butler H, et al. (2007) QuantiSNP: an Objective Bayes Hidden-Markov Model to detect and accurately map copy number variation using SNP genotyping data. Nucleic Acids Res 35: 20132025 . 